\title{
Measuring and Modeling Solar Irradiance on Vertical Surfaces
}

\author{
E. L. Maxwell \\ T. L. Stoffel \\ R. E. Bird
}

July 1986

Prepared under Task No. 3738.10

FTP No. 468

Solar Energy Research Institute

A Division of Midwest Research Institute

1617 Cole Boulevard

Golden, Colorado 80401

Prepared for the

U.S. Department of Energy

Contract No. DE-AC02-83CH10093 


\section{NOTICE}

This report was prepared as an account of work sponsored by the United States Government. Neither the United States nor the United States Department of Energy, nor any of their employees, nor any of their contractors, subcontractors, or their employees, makes any warranty, expressed or implied, or assumes any legal liability or responsibility for the accuracy, completeness or usefulness of any information, apparatus, product or process disclosed, or represénts that its use would not infringe privately owned rights.

Printed in the United States of America

Available from:

National Technical Information Service

U.S. Department of Commerce

5285 Port Royal Road

Springfield, VA 22161

Price: Microfiche A01

Printed Copy $\mathrm{AO3}$

Codes are used for pricing all publications. The code is determined by the number of pages in the publication. Information pertaining to the pricing codes can be found in the current issue of the following publications, which are generally available in most libraries: Energy Research Abstracts, (ERA); Government Reports Announcements and Index (GRA and I); Scientific and Technical Abstract Reports (STAR); and publication, NTIS-PR-360 available from NTIS at the above address. 
This report presents the first evaluations of five algorithms for converting the solar energy parameters most widely available from the national climatic data archives (global horizontal and direct normal solar irradiance) to global irradiance on tilted surfaces using measurements from the Solar Radiation Research Laboratory (SRRL) at the Solar Energy Research Institute (SERI). This evaluation was prepared by the Resource Assessment and Instrumentation Branch, Solar Electric Research Division. Support for this research was provided by the U.S. Department of Energy through the Passive Solar Program at the SERI Solar Heat Research Division.

The authors wish to recognize the following people for constructive technical review: Jay Burch, Roland Hulstrom, Kerri Hunter, and Claude Robbins of SERI; John Hay of the University of British Columbia; and Richard Perez of the State University of New York at Albany.

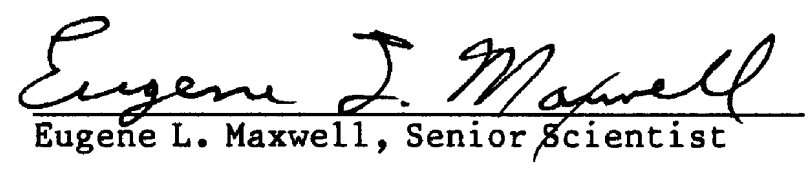

Approved for the

SOLAR ENERGY RESEARCH INSTITUTE

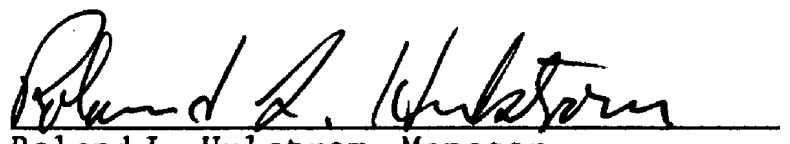

Roland L. Hulstrom, Manager

Resource As sessment and

Instrumentation Branch

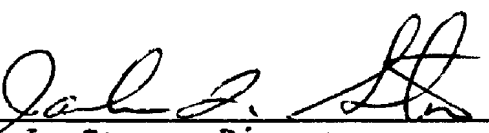

Jagk L. Stone, Director

Solar Electric Research Division 


\section{SUMMARY}

\section{Objective}

This report presents the first evaluations of five algorithms for converting global horizontal and direct normal solar irradiance components to global irradiance on tilted surfaces using measurements from the Solar Radiation Research Laboratory (SRRL) at the Solar Energy Research Institute (SERI).

\section{Discussion}

High resolution (15-min) measurements from eight thermopile radiometers oriented vertically in the four cardinal directions were available for a 169-day period ending 31 December 1984. Concurrent measurements of global horizontal and direct normal solar irradiance components were also used for the analysis. The pyranometers used in the experiment were intercompared on horizontal, north-facing, and south-facing vertical orientations before their deployment. The conversion algorithms each attempt to account for very complex atmospheric interactions with incoming solar radiation. The sky and ground radiance contributions to tilted surface irradiance are assumed to be isotropic, anisotropic, or a combination of the two regimes depending on the algorithm.

\section{Conclusions}

Results from the analysis of solar irradiance measurements on vertical surfaces for the period 22 July through 4 September indicate a general overestimate $(18 \%-46.5 \%)$ of solar irradiance on north-facing surfaces by all five algorithms. The best agreement with measured data was demonstrated for south-facing surfaces where all but one algorithm were within the present measurement accuracy $( \pm 5 \%)$. Estimates of global irradiance on east- and westfacing vertical surfaces ranged from slightly underpredicting $(-3 \%)$ to overpredicting by as much as $23 \%$ of the observed 15 -min data. Future research should emphasize the collection of data similar to that being obtained at SRRL, which will lead to greater understanding of atmospheric processes and diffuse sky irradiance distributions. 


\section{TABLE OF CONTENTS}

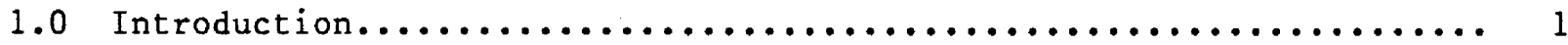

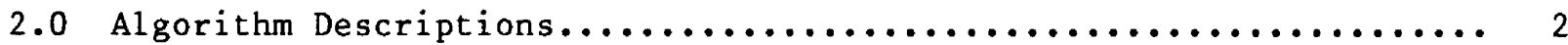

2.1 Direct Solar Beam Term............................ 2

2.2 Diffuse Sky Terms.............................. 2

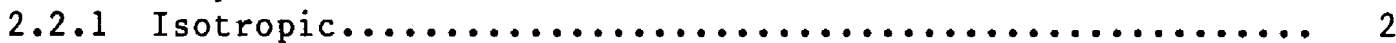

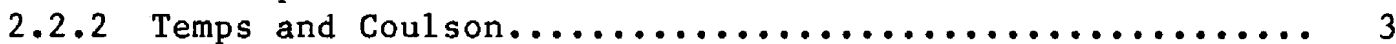

2.2 .3 Klucher............................... 4

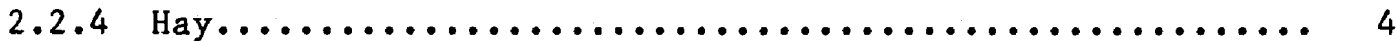

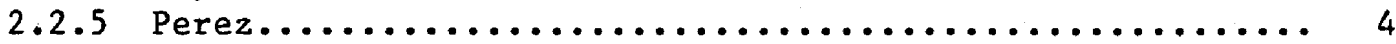

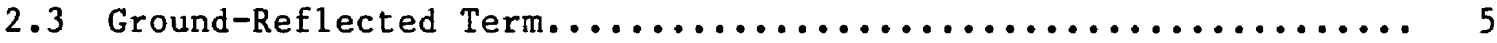

2.3 .1 Isotropic.................................... 6

2.3 .2 Temps and Coulson............................. 6

3.0 Measurements at SRRL............................... 7

3.1 Sensor Calibrations.............................. 7

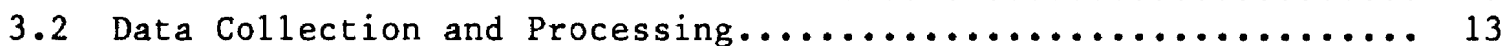

3.3 Data Plots...................................... 13

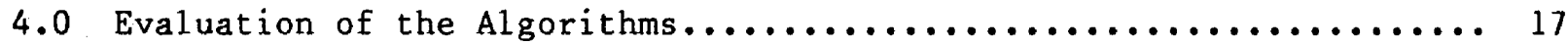

4.1 Intercomparisons of the Algorithms................. 17

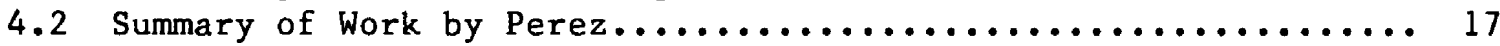

4.3 Evaluations Using Data Collected at SRRL................. 18

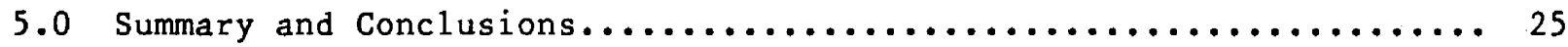

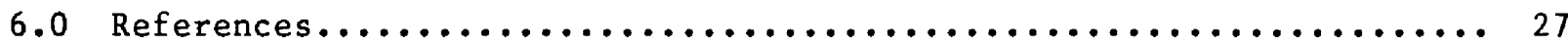




\section{LIST OF FIGURES}

$\underline{\text { Page }}$

3-1 The Radiometer Tower at the SERI Solar Radiation Research

Laboratory on South Table Mountain, Golden, Colo...............

3-2 Locations of Pyranometers on Radiometer Tower for Measuring Solar

Irradiance on Vertical Surfaces......................... g

3-3 Pyranometer Comparisons using Tilt Table Mounting Platform in a (a) Horizontal Position and (b) Vertical South-Facing Position..... 10

3-4 Results of Pyranometer Comparisons using Tilt Table Mounting Platform in Horizontal (O), South-Facing (S), and North-Facing (N)

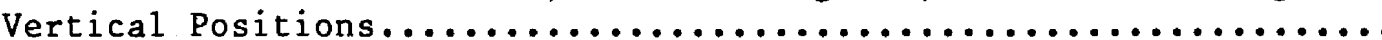

3-5 A Selected Clear Day (10 August 1984) of 15-min Averaged

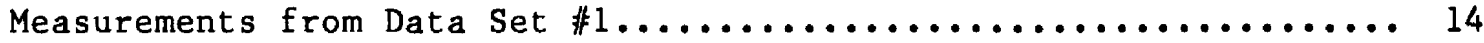

3-6 Measurements for a Selected Overcast Day (Cirrostratus Clouds)

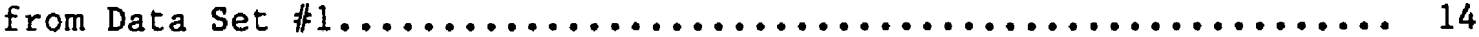

3-7 Measurements for a Selected Day from Data set $\# 2 \ldots \ldots \ldots \ldots \ldots \ldots \ldots$

3-8 Measurements from a Partly Cloudy Day in Data Set $\# 2 \ldots \ldots \ldots \ldots \ldots$

3-9 Typical Diurnal Pattern of Ground Albedo Measurements.......... 16

4-1a Solar Component Measurements for 6 September 1984 (Day 250)....... 22

4-1b Comparison of Measured Data for North-Facing Vertical Surface on September 6, 1984 and Tilt Model Estimates............... 22

4-2a Solar Component Measurements for 7 September 1984 (Day 251)....... 23

4-2b Comparison of Measured Data for North-Facing Vertical Surface on 7 September 1984 and Tilt Model Estimates................. 23

4-3 Comparison of Measured Data for North-Facing Vertical Surface on 6 September 1984 (clear sky) with Isotropic and Anisotropic Mode1 Estimates....................................... 24

4-4 Comparison of Measured Data for North-Facing Vertical Surface on 7 September 1984 (partly cloudy sky) with Isotropic and Anisotropic Model Estimates............................ 
LIST OF TABLES

$\underline{\text { Page }}$

2-1 Insolation Conversion Algorithms........................... 3

3-1 Results of Pyranometer Comparisons on Tilt Table.............. 12

4-1 Model Comparisons, North Facing-90 $0^{\circ}$ Tilt.................. 17

4-2 Summary of the Models' Performance........................ 19

4-3 Conversion Algorithm Performance during 41 Days............... 20

4-4 Average Daily Total Irradiance on Vertical Surfaces Measured at SRRL during the Period 23 July-4 September $1984 \ldots \ldots \ldots \ldots \ldots \ldots \ldots$...... 20 


\subsection{INTRODUCTION}

Passive solar heating, cooling, and daylighting systems utilize building apertures and external surfaces (walls) to collect or reject incident solar radiation. Those surfaces can generally be characterized in design performance simulations as flat plate collectors having a wide range of orientations described by various combinations of azimuth and elevation angles. Available solar radiation resource data for input to these simulations are limited to the historical measurements of global irradiance (direct solar beam plus diffuse sky irradiance components) on an unobstructed horizontal surface (SERI 1981a). Therefore, algorithms are needed to convert these measured values to estimates of the irradiance available to plane surfaces of any orientation. Several candidate conversion algorithms exist (Hay and McKay 1985). Their accuracy for other than south-facing orientations and application for a variety of climates continues to be a topic of research.

The FY 1984 objectives for this task were

- To evaluate the capability of existing conversion algorithms to estimate irradiance on $\mathrm{N}-\mathrm{E}-\mathrm{S}-\mathrm{W}$ vertical surfaces

- To initiate the measurement of irradiance on $\mathrm{N}-\mathrm{E}-\mathrm{S}-\mathrm{W}$ vertical surfaces to support the evaluation and development of conversion algorithms.

Initial plans called for three approaches to the evaluation of existing conversion algorithms:

1. Intercomparison of the performance of the algorithms under various hypothetical atmospheric conditions.

2. Comparison of actual measured data collected at universities participating in the Department of Energy's Solar Energy Meteorological Research Training Sites (DOE/SEMRTS) program (SERI 1981b, 1982) with estimated values from the algorithms.

3. Comparison of measured data collected at SERI's Solar Radiation Research Laboratory (SRRL) with estimated values from the algorithms.

The first approach was abandoned because of its limited usefulness to the variety of climates encountered in a general application of the alorithms.

Shortly after the task was undertaken it was determined that the second approach had already been used at the Atmospheric Sciences Research Center, State University of New York, Albany (Perez and Stewart 1984; Stewart and Perez 1984). Rather than duplicating their effort, we put greater effort into the collection of irradiance data at SRRL and the use of that data for the third approach given above. 


\subsection{ALGORITHM DESCRIPTIONS}

In general, conversion algorithms take the form

$$
I_{T}(\beta, \phi)=I_{S}(\beta, \phi)+I_{D}(\beta, \phi)+I_{G}(\beta, \phi),
$$

where

$$
\begin{aligned}
\mathrm{I}_{\mathrm{T}}(\beta, \phi) & =\text { the total irradiance on a tilted surface } \\
\mathrm{I}_{\mathrm{S}}(\beta, \phi) & =\text { the direct solar beam irradiance on the surface } \\
\mathrm{I}_{\mathrm{D}}(\beta, \phi) & =\text { the diffuse sky irradiance on the surface } \\
\mathrm{I}_{\mathrm{G}}(\beta, \phi) & =\text { the ground reflected irradiance on the surface } \\
\beta & =\text { the surface tilt angle (measured from the horizontal) } \\
\phi & =\text { the surface azimuth angle relative to the sun. }
\end{aligned}
$$

The five algorithms evaluated are 1 isted in Table 2-1, which also defines the general character of the diffuse sky and ground terms.

\subsection{Direct Solar Beam Term}

The direct solar beam term for each of the five algorithms is identical and is expressed by

$$
I_{S}(\beta, \phi)=I \cos \theta \text {, }
$$

where

$I=$ the intensity of the direct normal (beam) irradiance

$\theta=$ the incidence angle of the direct normal on the surface.

The direct normal is measured using a tracking pyrheliometer. The $5.7^{\circ} \mathrm{field}$ of view of most pyrheliometers encompasses the entire solar disk $\left(0.5^{\circ}\right)$ and most of the circumsolar region around the sun, which is produced by the forward scattering of radiation by the atmosphere.

\subsection{Diffuse sky Terms}

The diffuse sky terms are different for each of the algorithms evaluated. The simple isotropic term used by Liu and Jordan (1960) is described first, then the anisotropic modifiers of the other models are discussed.

\subsubsection{Isotropic}

The diffuse sky term of the algorithm is often referred to simply as the isotropic algorithm and is expressed as

$$
I_{D}(\beta)=1 / 2 I_{D}(0)(1+\cos \beta),
$$


Table 2-1. Insolation Conversion Algorithms

\begin{tabular}{lll}
\hline Algorithm & Diffuse Sky Term & Ground Term \\
\hline Isotropic & Clear or cloudy and isotropic & Isotropic \\
Temps and Coulson & Clear only and anisotropic & Anistropic \\
Klucher & Clear or cloudy and anisotropic & None \\
Hay & Clear or cloudy and anisotropic & Isotropic \\
Perez & Clear or cloudy and anisotropic & None \\
\hline
\end{tabular}

where

$$
\begin{aligned}
\mathrm{I}_{D}(0) & =\text { the measured diffuse sky irradiance on a horizontal surface }(\beta=0) \\
\beta & =\text { the surface tilt angle. }
\end{aligned}
$$

This expression assumes uniform radiance from each portion of the sky, i.e., isotropic diffuse irradiance from all directions above the surface, resulting in no dependence on azimuth angle, $\phi$.

\subsubsection{Temps and Coulson}

Temps and Coulson (1977) added a degree of complexity to the isotropic diffuse sky term:

$$
I_{D}(\beta)=1 / 2 I_{D}(0)(1+\cos \beta) M_{1} M_{2},
$$

where

$$
\begin{aligned}
& M_{1}=\left[1+\sin ^{3}(\beta / 2)\right] \\
& M_{2}=\left(1+\cos ^{2} \theta \sin ^{3} z\right) \\
& \theta=\text { the angle of incidence of the direct beam on the surface } \\
& Z=\text { the solar zenith angle. }
\end{aligned}
$$

$M_{1}$ is an anisotropic modifier to account for horizon brightening, and $M_{2}$ is an anisotropic modifier to account for the brightening around the solar disk (circumsolar radiation). $M_{2}$ is a potential source of error since the measurement of the direct normal beam (I) encompasses a large part of the circumsolar radiation. Note also that $M_{2}$ does not include any means to account for the increase in circumsolar radiation with the onset of cloud cover, which eventually leads to an anisotropic sky under overcast conditions. It is for this reason that the Temps and Coulson algorithm is applicable to only clear conditions. Under overcast skies there is horizon "darkening"-another reason why the Temps and Coulson algorithm is inappropriate for other than clear sky conditions. 


\subsubsection{Klucher}

A refinement of the diffuse sky term provided by Klucher (1978) adds a cloudiness function (F) to the Temps and Coulson algorithm; i.e.,

$$
I_{D}(\beta)=1 / 2 I_{D}(0)(1+\cos \beta) M_{3} M_{4} \text {, }
$$

where

$$
\begin{aligned}
M_{3} & =\left[1+F \sin ^{3}(\beta / 2)\right] \\
M_{4} & =\left[1-F \cos ^{2} \theta \sin ^{3} Z\right] \\
F & =\left\{1-\left[I_{D}(0) / I_{T}(0)\right]^{2}\right\} .
\end{aligned}
$$

An examination of the cloudiness function reveals that under overcast skies $\left[I_{D}(0)=I_{T}(0)\right]$ the Klucher diffuse sky term reduces to the isotropic term of Liu and Jordan, as was the intent.

\subsubsection{Hay}

The diffuse sky term described by Hay and Davies (1978) also provides for anisotropy by considering both circumsolar and isotropic terms. The diffuse sky term in the Hay algorithm is expressed as

$$
I_{D}(\beta)=I_{D}(0)\left[\left(I \cos \theta / I_{0} \cos Z\right)+1 / 2(1+\cos \beta)\left(1-I / I_{0}\right)\right],
$$

where

$I=$ the direct normal (beam) irradiance from the sun

$I_{0}=$ the extraterrestrial direct normal (beam).

The first term inside the brackets represents circumsolar radiation whose intensity is a function of atmospheric transmissivity ( $/ / I_{0}$ ), the angle of incidence of the direct beam, and the solar zenith angle. The inverse relation with $\cos Z$ represents an increase in circumsolar radiation with an increase in air mass (increasing solar zenith angle). The second term represents the isotropic radiation from the sky that increases with decreasing transmissivity; i.e., with increasing turbidity or cloud cover. Note that the Hay algorithm simplifies to the isotropic case for overcast conditions.

\subsubsection{Perez}

This algorithm, like the Klucher and the Temps and Coulson algorithms, accounts for horizon brightening as well as circumsolar radiation (Perez and Stewart 1984). This is accomplished by describing the sky dome as isotropic except for a circular region of variable size around the sun and a horizontal band of variable height at the horizon. The equation for the diffuse sky term of the Perez algorithm is 


$$
\begin{gathered}
I_{D}(\beta)=I_{D}(0) \frac{1 / 2(1+\cos \beta)+2\left(F_{1}-1\right)(1-\cos \alpha) Z_{c}}{1+2\left(F_{1}-1\right)(1-\cos \alpha) Z_{h}} . . \\
\quad \cdot \frac{+2\left(F_{2}-1\right) \xi / \pi \sin \xi^{\prime}}{+1 / 2(1-\cos 2 \xi)\left(F_{2}-1\right)},
\end{gathered}
$$

where

$\mathrm{F}_{1}=$ the ratio of the radiance in the circumsolar region to isotropic sky radiance

$\mathrm{F}_{2}=$ the ratio of the radiance in the horizon band to the isotropic sky

$\alpha=$ the half angle width of the circumsolar region

$\xi=$ the angular width of the horizon band

$\xi^{\prime}=$ the altitude angle of the apex of the horizon band with respect to the tilted surface

$z_{c}=\cos \theta$

$z_{c}=\frac{\left(x_{c} \sin x_{c}\right)}{\alpha}$

$[0<\theta<(\pi / 2-\alpha)]$

$z_{c}=0$

$(\pi / 2-\alpha)<\theta<(\pi / 2+\alpha)]$

$x_{c}=(\pi / 2+\alpha-\theta) / 2$

$[\theta>(\pi / 2+\alpha)]$

$\theta=$ angle of incidence of circumsolar radiation on a tilted surface

$\mathrm{Z}_{\mathrm{h}}=\cos \mathrm{Z} \quad[0<\mathrm{Z}<(\pi / 2-\alpha)]$

$z_{h}=\frac{\left(x_{h} \sin x_{h}\right)}{\alpha} \quad[z>(\pi / 2-\alpha)]$

$x_{h}=(\pi / 2+a-z) / 2$

$\mathrm{Z}=$ angle of incidence of circumsolar radiation on a horizontal surface.

The terms $F_{1}$ and $F_{2}$ are empirically derived from measured data at the location of interest. They are a function of the solar zenith angles, $I_{D}(0)$ and $I(0)$, and are available in the form of $5 \times 6 \times 7$ matrices. The empirical nature of these terms is a distinct limitation of data sets similar to those at the State University of New York at Albany.

\subsection{Ground-Reflected Term}

The approach for estimating the contribution of ground-reflected solar irradiance can be classified as either isotropic (uniform with respect to direction) or anisotropic (directional). The Klucher algorithm was developed from data collected from pyranometers shielded from this radiation component by artificial ground planes and therefore does not account for either case. With the exception of the Temps and Coulson algorithm, which accounts for the azimuthal dependence of the ground-reflected components, the remaining algorithms assume isotropy for this term in Eq. 2-1. 


\subsubsection{Isotropic}

The ground-reflected term for these algorithms is given by

$$
I_{G}(\beta)=1 / 2 I_{T}(0) R_{G}(1-\cos \beta) \text {, }
$$

where

$$
\begin{aligned}
\mathrm{I}_{\mathrm{T}}(0) & =\text { the measured global horizontal irradiance } \\
\mathrm{R}_{\mathrm{G}} & =\text { the ground albedo. }
\end{aligned}
$$

This algorithm assumes the ground is a homogeneous Lambertian surface (perfect diffuser) surrounding the tilted surface.

\subsubsection{Temps and Coulson}

The Temps and Coulson term for ground-reflected radiation is given by

$$
I_{G}(\beta, \phi)=I_{T}(0) R_{G} M_{5} M_{6},
$$

where

$$
\begin{aligned}
M_{5}= & {\left[1-\cos ^{2}(\beta / 2)\right] } \\
M_{6}= & {\left[1+\sin ^{2}(\mathrm{Z} / 2) \text { |cos } \phi \mid\right] } \\
\phi= & \text { the titled surface azimuth angle relative to the sun }(\phi=0 \text { when the } \\
& \text { surface is pointed toward the sun). }
\end{aligned}
$$

The equation represents a ground surface exhibiting forward scattering, which increases with the solar zenith angle. 


\subsection{MEASUREMENTS AT SRRL}

Pyranometers were installed at the Solar Radiation Research Laboratory (SRRL) using the radiometer tower designed for monitoring solar irradiance on vertical surfaces oriented in the four cardinal directions (Figure 3-1). The instruments were positioned to measure the global irradiance on each of the four vertical surfaces as well as the diffuse sky and ground-reflected components for the north- and south-facing orientations. Global horizontal and ground-reflected irradiance on downward-facing horizontal surfaces complete the list of ten Eppley PSP pyranometers deployed for the experiment. The arrangement of sensors, artificial horizons, and radiation baffles to accomplish the measurements is shown in Figure 3-2.

In addition to the array of sensors set up for this task, SRRL routinely monitors global horizontal, direct normal, and diffuse horizontal irradiances. These data provide the inputs corresponding to each term in the conversion algorithm (Eq. 2-1). In addition to the irradiance values, ground albedo"is calculated by ratioing the downward-looking horizontal data with the global horizontal data.

\subsection{Sensor Calibrations}

A11 of the Eppley PSPs used for this task were calibrated and intercompared by placing them on a large tilt table with SERI's working standard PSP and collecting simultaneous global data for horizontal, south-facing vertical, and north-facing vertical planes as shown in Figure 3-3. Note the presence of white "collars," which were installed around the instrument body below the sun shade. These units provide additional shielding of the instrument body, which serves as the reference cold junction for the thermopile sensor, from the direct radiation. This reduces the presence of thermal gradients when the pyranometer is mounted in other than a horizontal position. The collars were used during all intercomparisons and final installation on the radiometer tower. Several days of 1 -min data were obtained and analyzed for each orientation. The calibration results are summarized in Table 3-1.

From these data, the selection of PSPs for each position on the radiometer tower was made so as to minimize differences among sensors for which data comparisons would be critical. A minimum of two days of measurements for each tilt table orientation (horizontal, vertical north-facing, and vertical southfacing) was analyzed. Instrument selection was based on the minimum relative variance of the $1-\mathrm{min}$ ratios of the output signal from the test pyranometer (millivolts) to the irradiance measured by the SERI reference pyranometer (watts per square meter). The calibration factor for each instrument was determined from this ratio. The mean value (calibration factor) and standard deviation of this ratio were computed for three groups of data determined by the tilt table orientations. The relative variance of the calibration factor was computed for each instrument using the formula: Relative Variance $=100 \times$ Standard Deviation/Mean.

The relative performance of the test pyranometers with respect to the reference unit is shown in Eigure 3-4. The varability of the calibration 


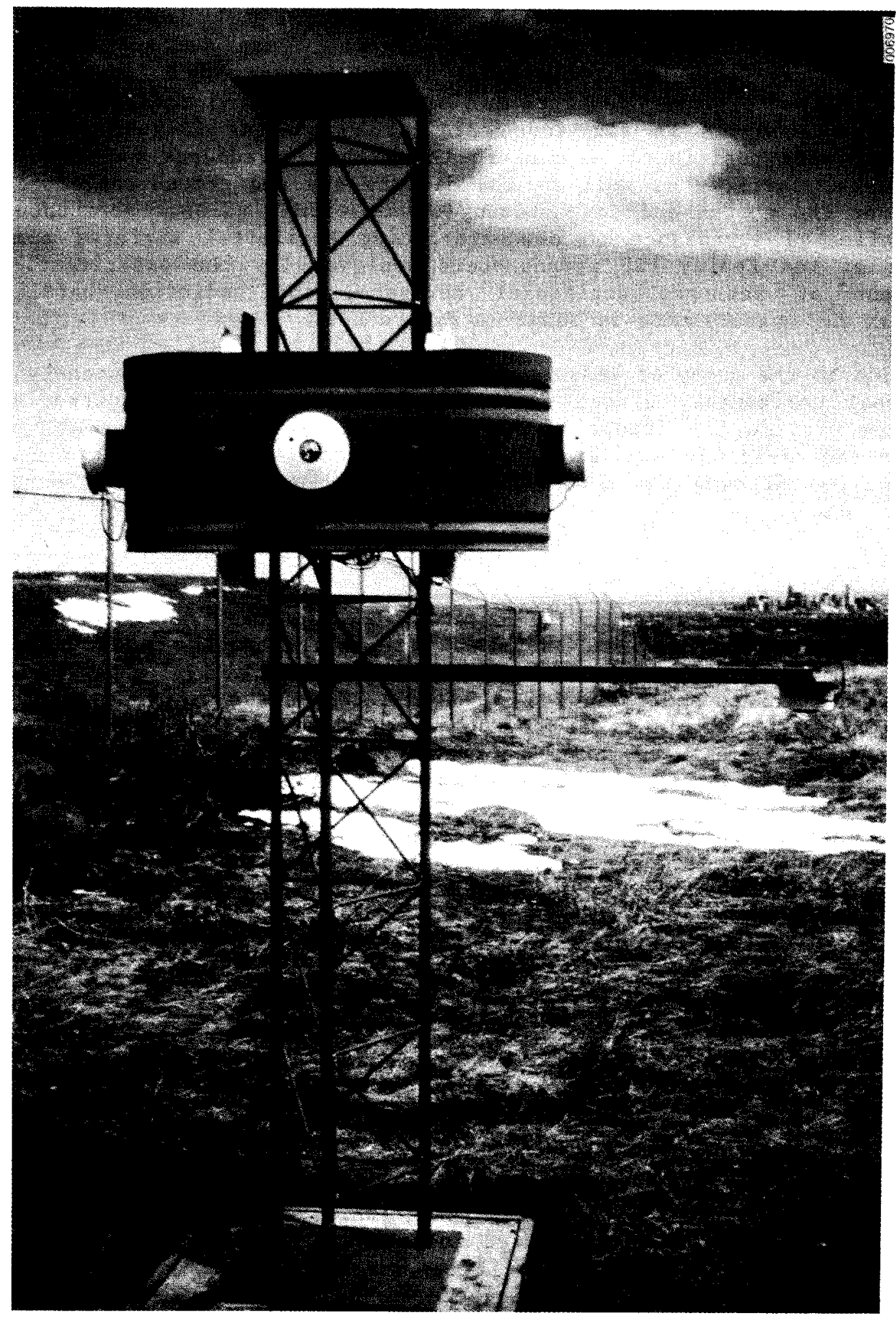

Figure 3-1. The Radiometer Tower at the SERI Solar Radiation Research Laboratory on South Table Mountain, Golden, Colo. View looking east toward Denver skyline. 


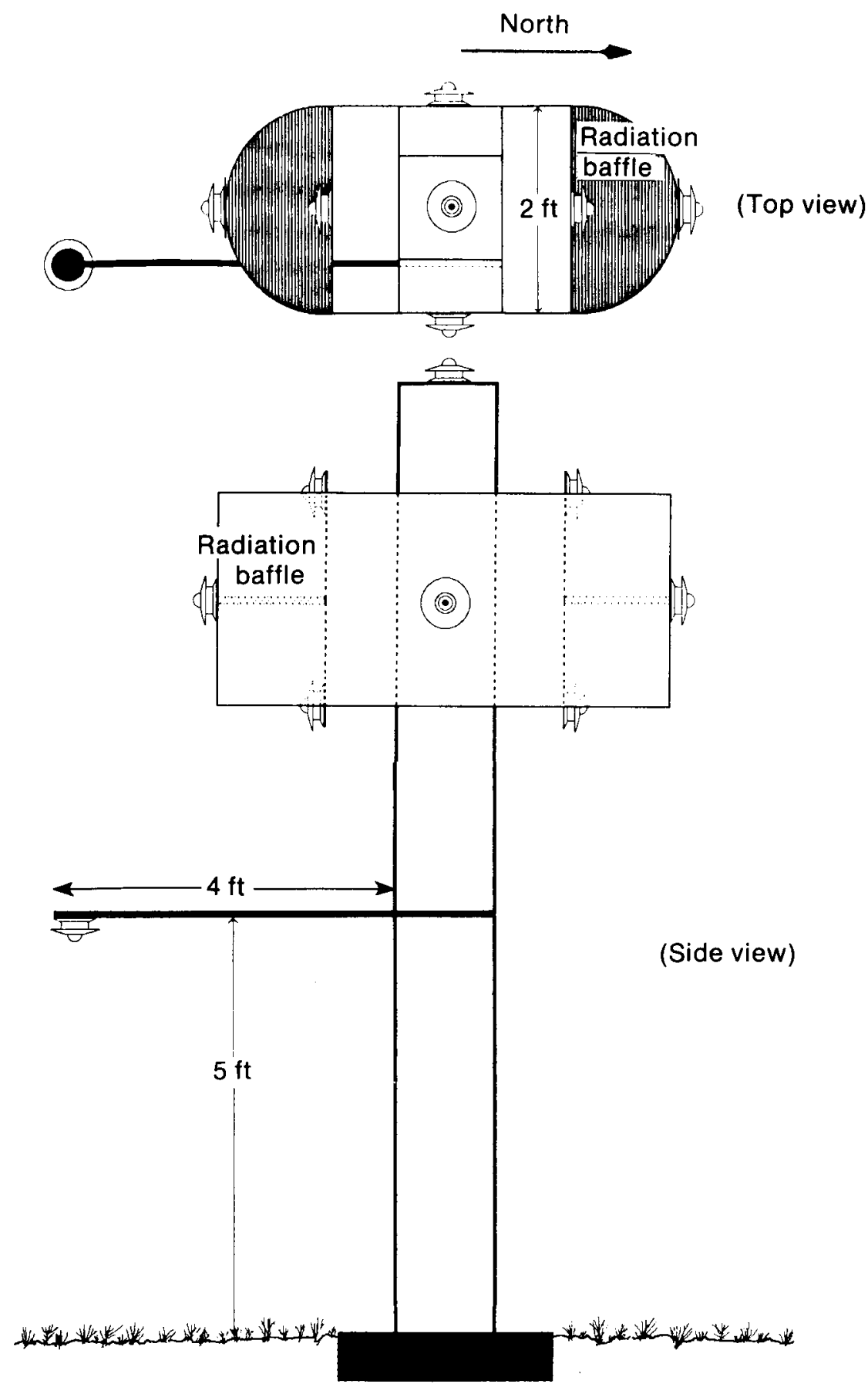

Figure 3-2. Locations of Pyranometers on Radiometer Tower for Measuring Solar Irradiance on Vertical Surfaces 

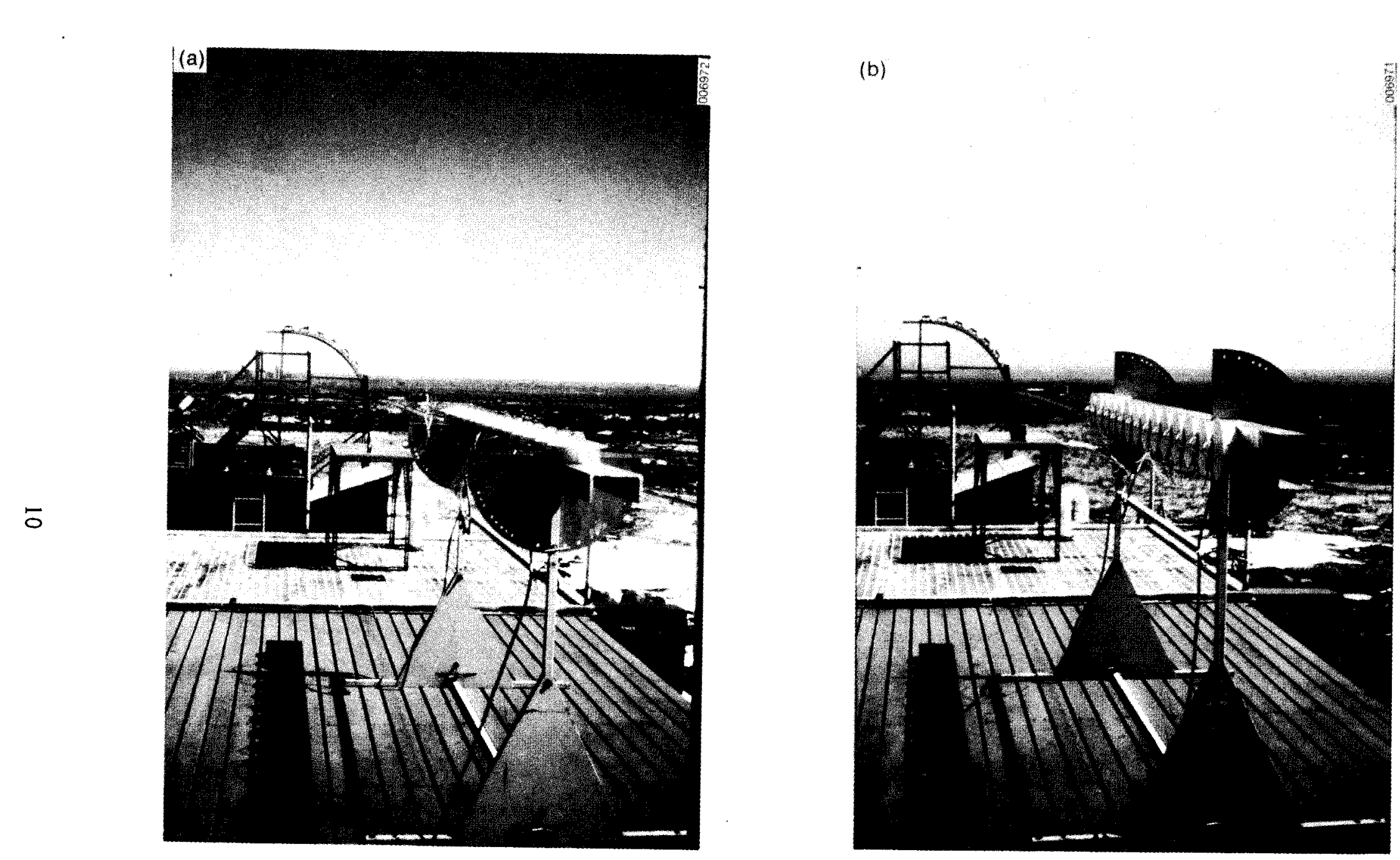

Figure 3-3. Pyranometer Comparisons using Tilt Table Mounting Platform in a (a) Horizontal Position and (b) Vertical South-Facing Position 


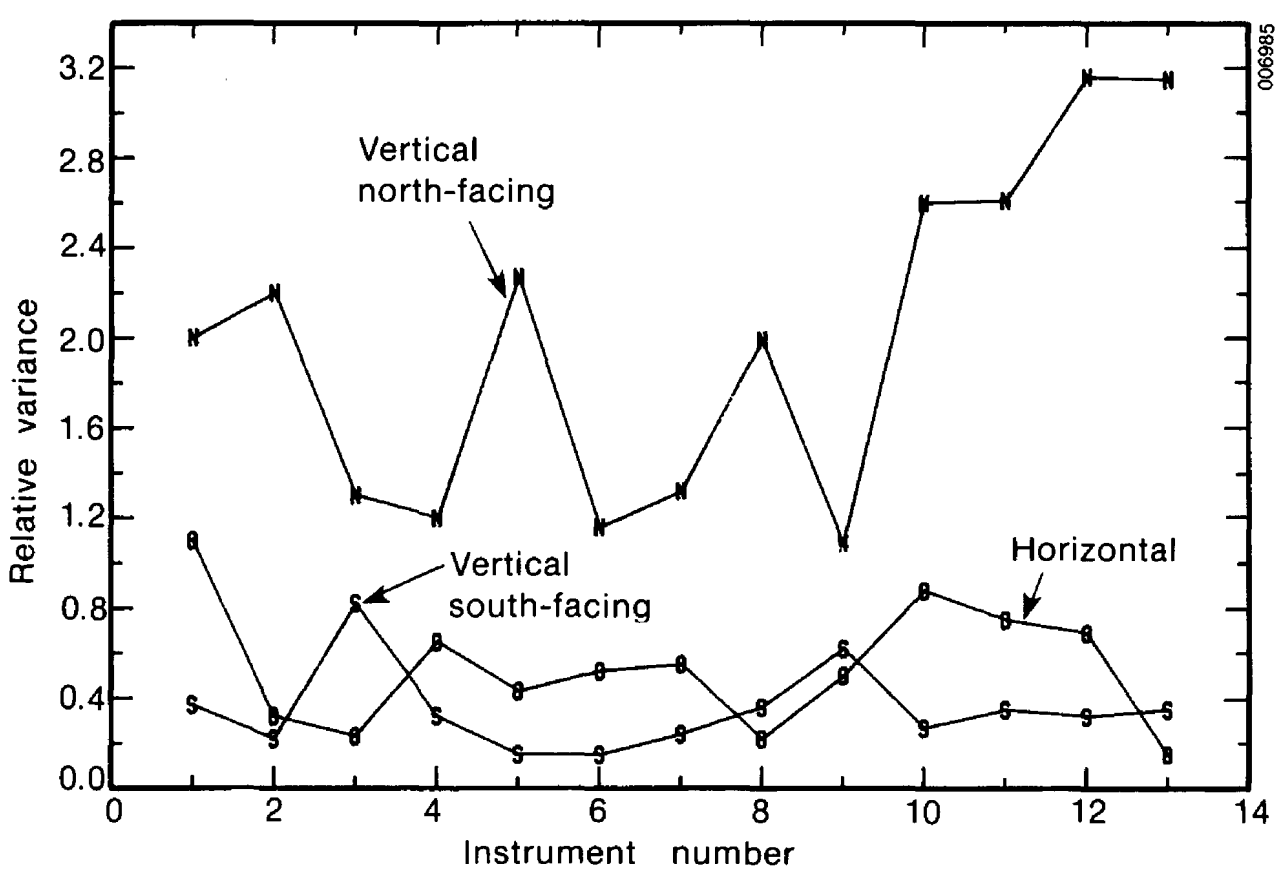

PSP INTERCOMPARISONS: TILT TABLE APRIL 4-13, 1984

$\begin{array}{ccl}\begin{array}{c}\text { INSTRUMENT } \\ \text { NUMBER }\end{array} & \begin{array}{c}\text { SERIAL } \\ \text { NUMBER }\end{array} & \begin{array}{l}\text { MEASUREMENT } \\ \text { PARAMETER }\end{array} \\ 1 & 13674 \mathrm{~F} 3 & \begin{array}{l}\text { (Not Used) } \\ \text { South-Sky }\end{array} \\ 2 & 17798 \mathrm{~F} 3 & \text { North-sky } \\ 3 & 17799 \mathrm{~F} 3 & \text { North-Ground } \\ 4 & 17800 \mathrm{~F} 3 & \text { South-Ground } \\ 5 & 17362 \mathrm{~F} 3 & \text { South-Global } \\ 6 & 17879 \mathrm{~F} 3 & \text { Albedo } \\ 7 & 18035 \mathrm{~F} 3 & \text { West-Global } \\ 8 & 13036 \mathrm{~F} 3 & \text { North-Global } \\ 9 & 18039 \mathrm{~F} 3 & \text { Diffuse Horizontal } \\ 10 & 18040 \mathrm{~F} 3 & \text { East-Global } \\ 11 & 13078 \mathrm{~F} 3 & \text { (Not Used) } \\ 12 & 20058 \mathrm{~F} 3 & \text { Global Horizontal }\end{array}$

Figure 3-4. Results of Pyranometer Comparisons using Tilt Table Mounting Platform in Horizontal ( 0$)$, South-Facing (s), and North-Facing (N) Vertical Positions. Installation of instruments of the radiometer tower (measurement parameter) was determined from these data. 
Table 3-1. Results of Pyranometer Comparisons on Tilt Table

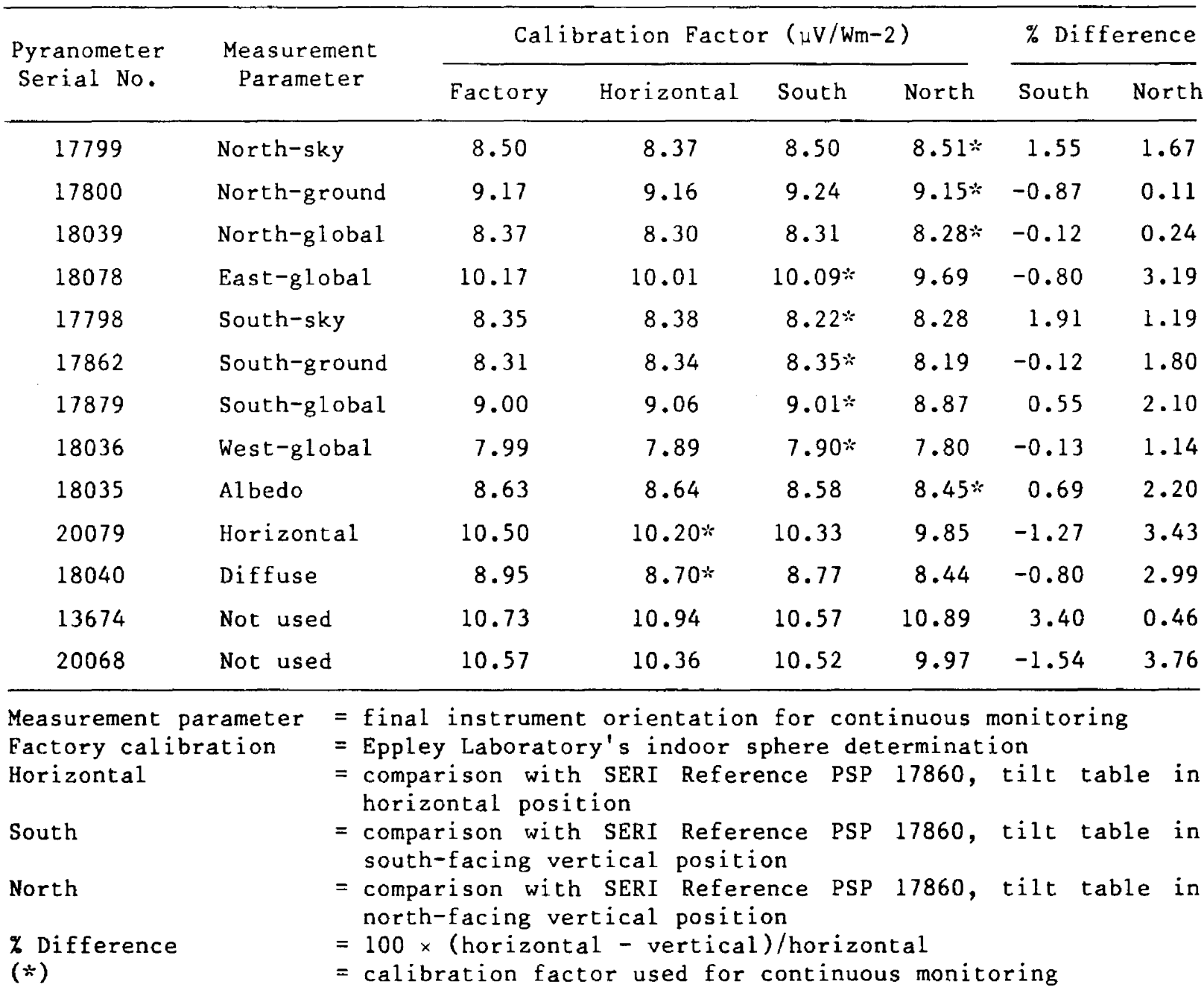

factor depends on the particular instrument and its orientation. The ability of the instrument to view the direct (beam) radiation component appears to minimize the relative performance differences between all instruments and the SERI reference pyranometer. The reference pyranometer may itself undergo changes in sensitivity when instrument orientation, ambient air temperature, solar irradiance levels, or other factors change. These intercomparisons cannot ensure the absolute measurement accuracy of the pyranometers. The overall agreement of the calibrations is within the generally accepted tolerance of $\pm 5 \%$ for these thermopile instruments (SERI 1982b).

The selection of pyranometer orientation/location on the radiometer tower was based on the results shown in Figure 3-4. For example, the three north-facing sensors were selected from those that compared best on a north-facing plane. The calibration factors for the east- and west-facing pyranometers were determined from the tilt table comparisons exhibiting the least relative variance 
from the reference instrument after selecting the north- and south-facing instruments. The cosine response of the east-and west-facing pyranometers is particularly important since the irradiance levels are generally high near solar noon when the sun is setting or rising (incidence angle $=90^{\circ}$ ) on these instruments.

\subsection{Data Collection and Processing}

Plans called for the simultaneous collection of 1 -min data from all nine sensors in the test array, plus the three baseline monitors. However, this task was initiated during the transition period between the operation of an interim research laboratory and the establishment of a permanent facility at SRRL. SRRL has yet to become fully operational; and therefore, data collection has been 1 imited to $15-m i n$ data from seven sensors at a time. At this time, the following data sets have been collected:

Data Set No. 1

(from 22 July to 4 Sept. 1984)

Global horizontal

Direct normal

Global north vertical

Global east vertical

Global south vertical

Global west vertical

Ground reflected horizontal
Data Set No. 2

(from 5 Sept. to 30 Sept. 1984)

Global horizontal

Direct normal

Diffuse horizontal

Global south vertical

Global north vertical

Sky north vertical

Ground north vertical

In the near future, a much improved data acquisition capability will be in operation at SRRL. This will permit the collection of data from all sensors at the same time with any desired integration time. The results in this report have been derived from the two data sets noted above.

\subsection{Data P1ots}

Figures 3-5 and 3-6 are plots of typical data from data set No. 1. Figure 3-5 shows the symmetry of a very clear day on 10 August 1984 . It is particularly interesting to note that in the absence of the direct beam because of surface orientation, the irradiance on all four surfaces is about the same. Furthermore, on this midsummer day, the daily total energy received on east, south, and west vertical surfaces is about the same $\left(17.9,13.5\right.$, and $17.5 \mathrm{MJ} / \mathrm{m}^{2}$, respectively).

The irradiance received on a cloudy day, 6 August 1984, is shown in Figure 3-6. Some direct beam irradiance was recorded between 0500 and 0800 ; but thereafter, the sun did not shine on the SRRL. Between 0800 and 1030, a low heavy overcast developed. This cloud cover thinned out between 1030 and 1330, but was more or less uniform across the sky dome. These recorded observations are confirmed by the variations in irradiance shown in Figure 3-6.

Data for a clear day and partly cloudy day from the second data set are shown in Figures 3-7 and 3-8, respectively. On the clear day, an interesting relationship is observed between the north-vertical diffuse sky irradiance and the 


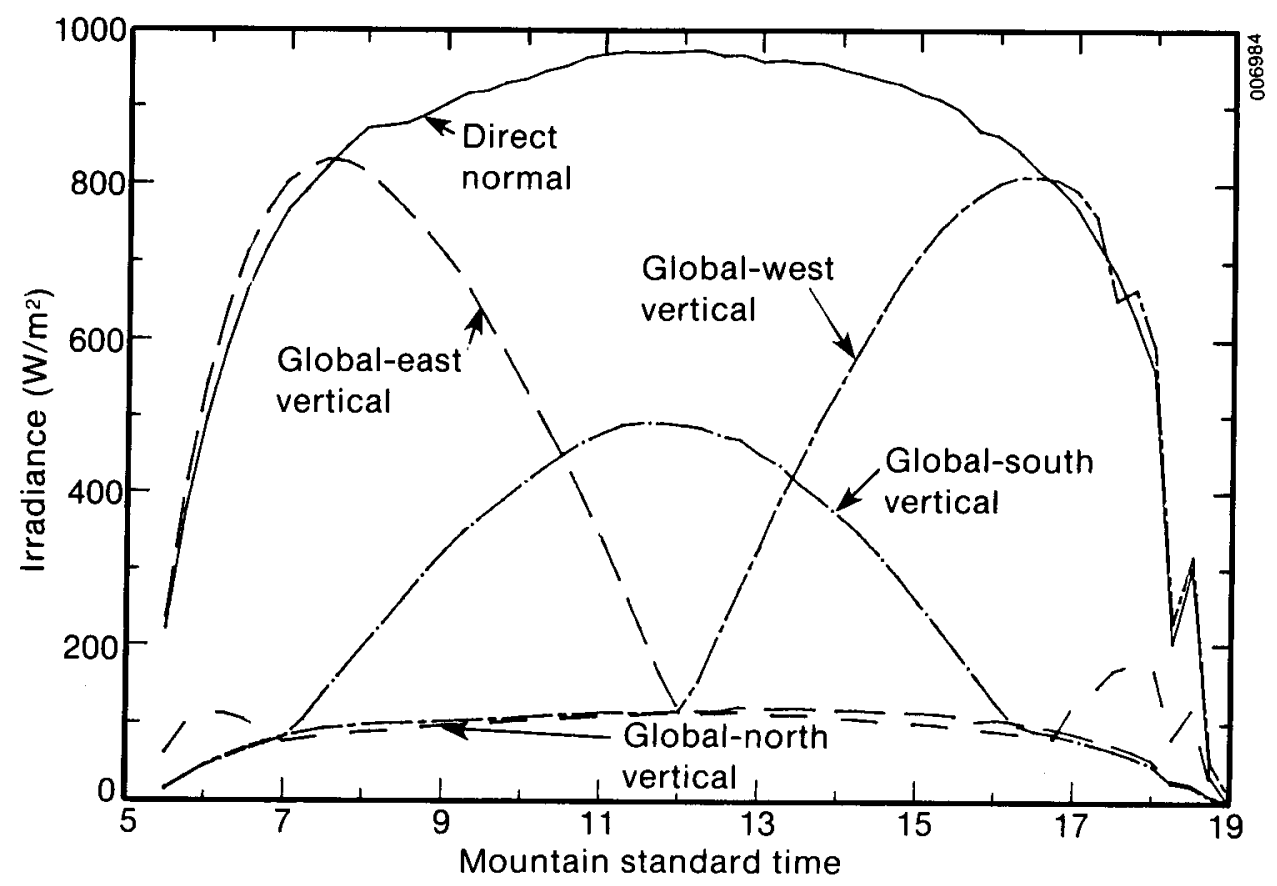

Figure 3-5. A Selected Clear Day (10 August 1984) of 15-min Averaged Measurements from Data Set $\$ 1$

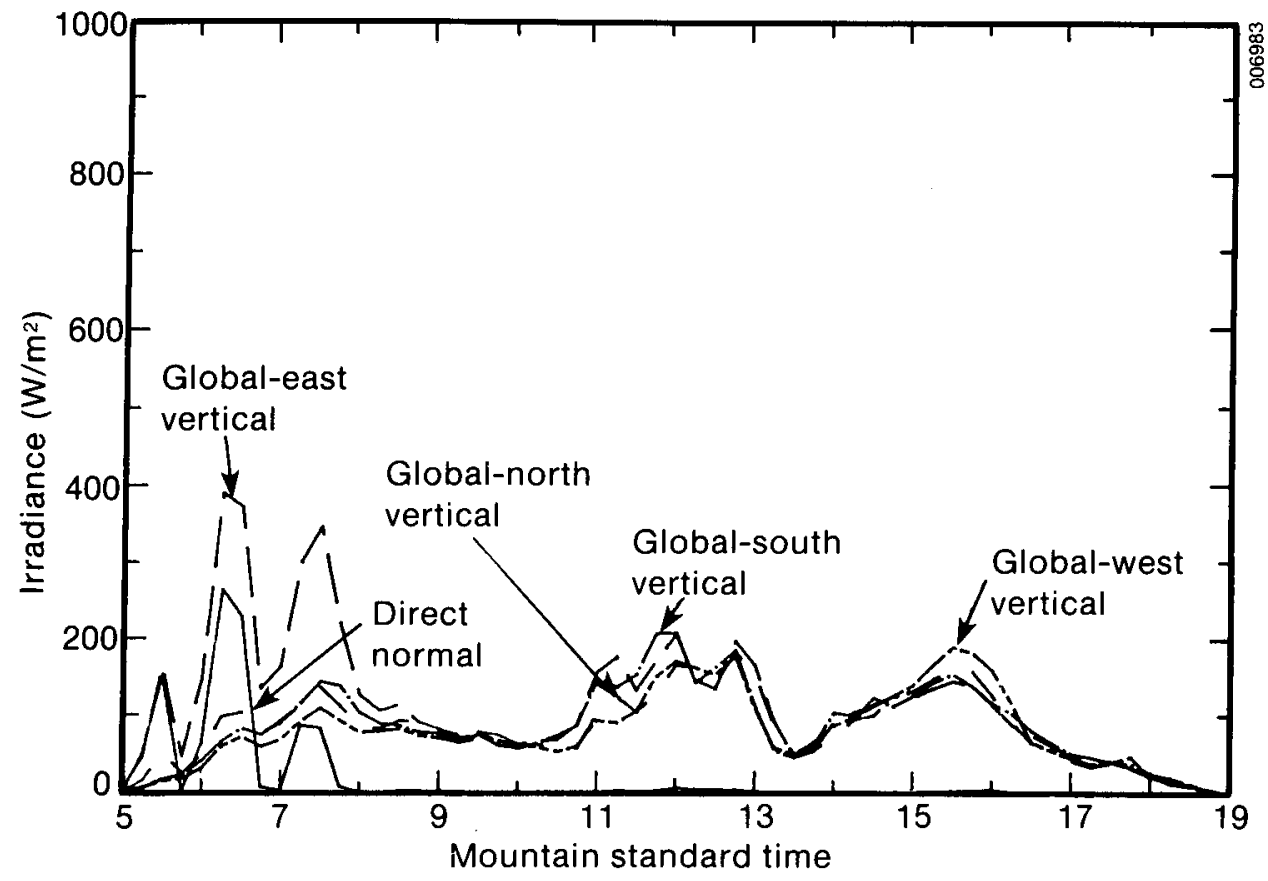

Figure 3-6. Measurements for a Selected Overcast Day (Cirrostratus Clouds) from Data Set $\$ 1$ 
north-vertical ground-reflected irradiance. In early morning and late afternoon the diffuse sky irradiance reaches a maximum and is greater than the ground-reflected irradiance. By midmorning, the ground-reflected irradiance is about twice the diffuse sky. This is, of course, consistent with the gradual increase in the irradiance on horizontal surfaces as shown on the figure. The region around the tower was a natural surface with grass, forbs, and some bare soil showing. At this time of year, the vegetation is mostly senescent. The measured albedo just two days earlier is shown in Figure 3-9.

Figure 3-8 presents an even more interesting situation. Early in the morning a cold front moved through the area producing a dark layer of alto-stratus clouds that moved from the northwest early in the morning until most of the sky was covered by 0830 . These stratus clouds produced a sky irradiance that was approximately double the ground-reflected component, just the opposite of the relative levels observed on the previous clear day. At about 1230, this stratus condition began to break up, and at about 1315, we noted a crossover of the sky and ground components. The presence of alto-cumulus in the afternoon produced the jagged appearance of the direct normal and maintained the diffuse sky irradiance at about the same level as the ground-reflected term.

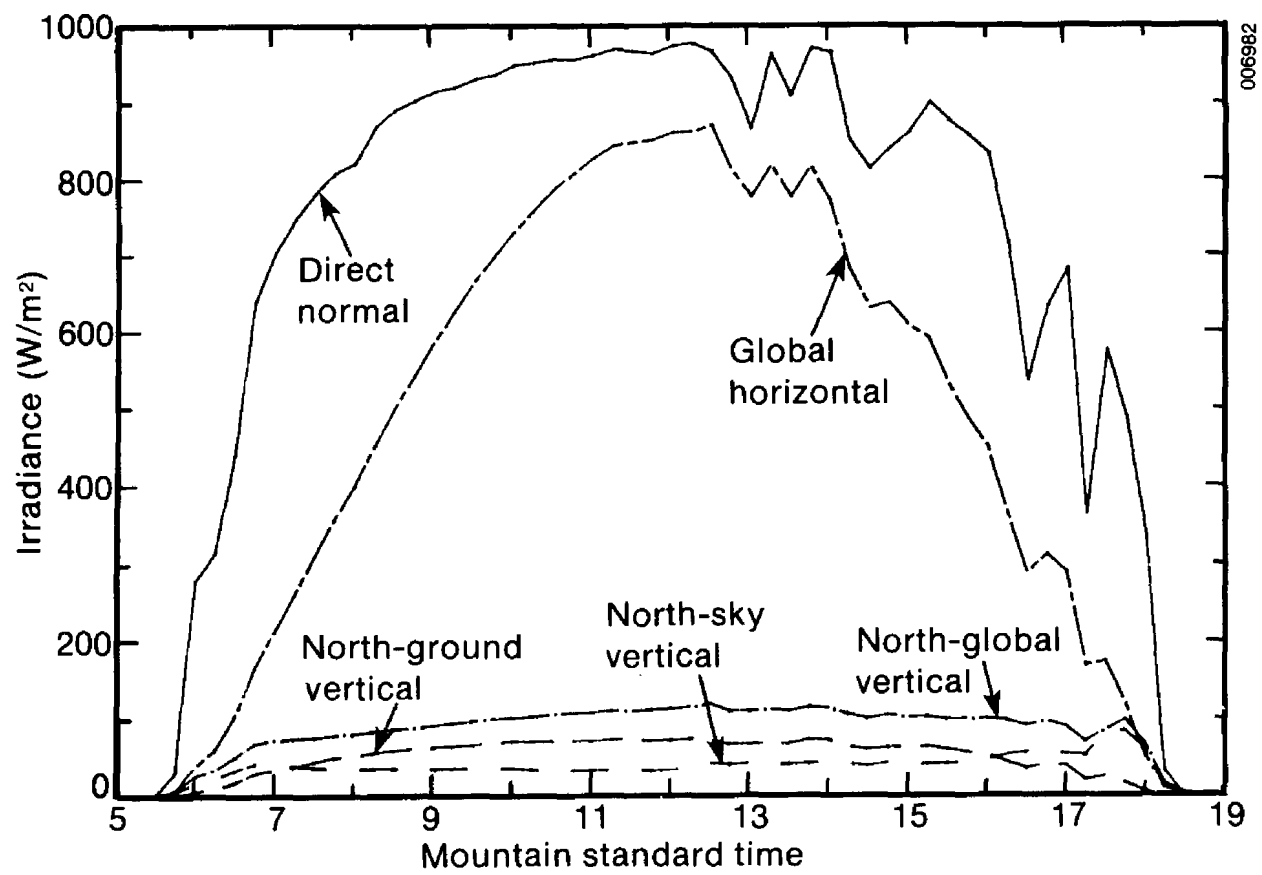

Figure 3-7. Measurements for a Selected Day from Data Set \$2. Clear sky in the morning with thin cirrus clouds in the afternoon. 


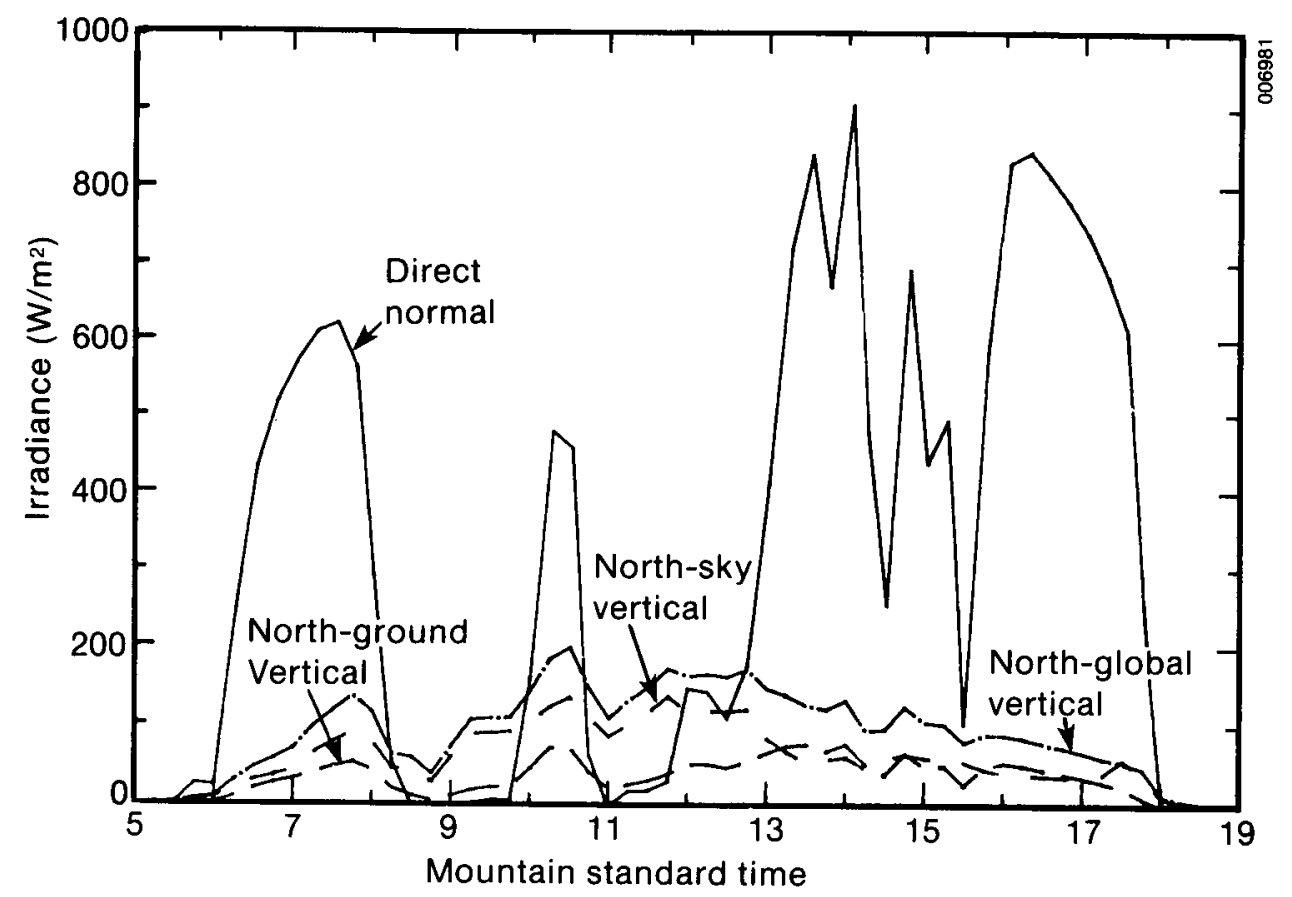

Figure 3-8. Measurements from a Partly Cloudy Day in Data Set $\$ 2$

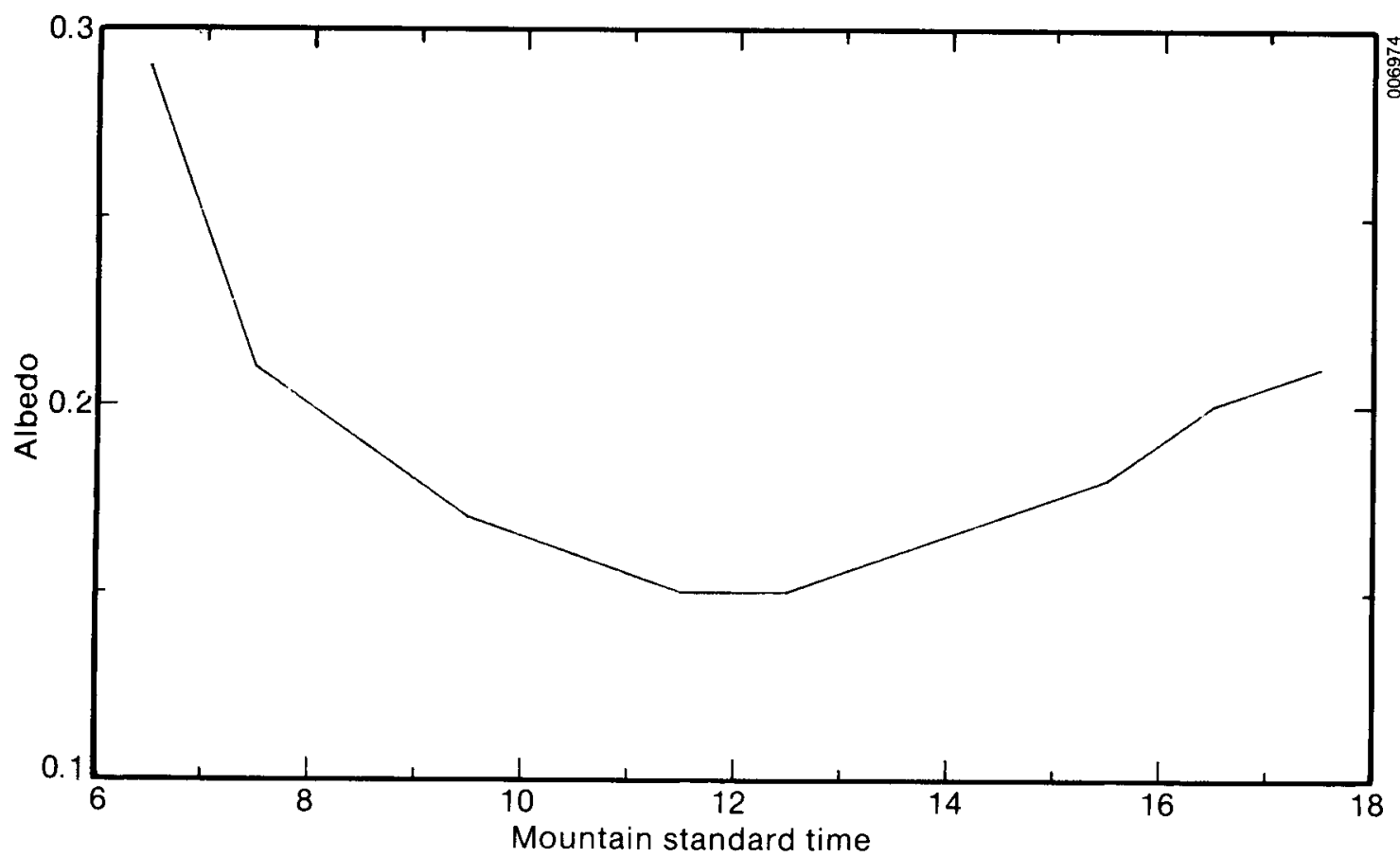

Figure 3-9. Typical Diurnal Pattern of Ground Albedo Measurements 


\subsection{EVALUATION OF THE ALGORITHMS}

The conversion algorithms described in section 2.0 have been evaluated in several ways. First, an intercomparison of the models under different atmospheric conditions reveals certain characteristics such as their regression to an isotropic form under overcast skies. The comparisons with measured data, which are reported here, include a brief summary of results reported by Perez and Stewart (1984). Comparisons with the two data sets available from the SRRL conclude this section.

\subsection{Intercomparisons of the Algorithms}

The results reported here excluded the ground term since some of the algorithms do not have such a term. The numbers in Table 4-1 are values of irradiance for individual days that were overcast, partly cloudy, or clear. Measured data were available for these atmospheric conditions for the direct normal, global horizontal, and diffuse sky components. This particular data set, used at the start of this task, did not include measurements on vertical surfaces. Hence, the models could be intercompared but not compared in absolute terms.

The results show up to $30 \%$ differences under clear skies in June and almost identical results under overcast skies any time of the year. This is a result of all the models regressing to the isotropic model under overcast conditions.

\subsection{Summary of Work by Perez}

The State University of New York at Albany (SUNYA) collected an accurate data base of solar radiation measurements from 1977 to 1981 under the DOE-funded Solar Energy Meteorological Research Training Sites (SEMRTS) program. The data included measurements on vertical surfaces with $\mathrm{N}-\mathrm{E}-\mathrm{S}-\mathrm{W}$ azimuths and measurements on other tilted south-facing surfaces. An artificial horizon shielded the sensors from the ground-reflected radiation.

Perez and Stewart used that data base to evaluate the isotropic (Liu and Jordan), Klucher, and Hay algorithms, as well as a new model they developed

Table 4-1. Model Comparisons, North Facing-90 Tilt (Daily Total Irradiance $-\mathrm{kJ} / \mathrm{m}^{2}$ )

\begin{tabular}{llccrr}
\hline Month & Condition & Isotropic & Klucher & Hay & Perez \\
\hline June & Clear & 8349 & 9648 & 6882 & 7479 \\
June & Partly cloudy & 4375 & 4487 & 4332 & 4000 \\
June & Overcast & 1525 & 1528 & 1525 & 1531 \\
December & Clear & 3182 & 3448 & 2912 & 3148 \\
December & Part1y cloudy & 1865 & 1967 & 1796 & 1679 \\
December & Overcast & 632 & 633 & 632 & 629 \\
\hline
\end{tabular}


and called the Perez model. In their analysis, they removed the direct beam component from the global measurements to permit evaluation of the diffuse sky component by itself.

A summary of the results of their evaluation is given in Table 4-2. It is apparent that the isotropic, Klucher, and Hay algorithms perform better on south-facing surfaces than on east, west, or north surfaces. The Perez model does better on the E-W surfaces, but still seems to overestimate on a northvertical surface, although still exhibiting a lower RMS error. North-facing surfaces produce the largest relative errors for all the algorithms as might be expected for the lower irradiance levels associated with this orientation.

\subsection{Evaluations Using Data Collected at SRRL}

As described in Section 3.2, data set No, 1 contains 41 days of data with global measurements on $\mathrm{N}-\mathrm{E}-\mathrm{S}-\mathrm{W}$ vertical surfaces. Table 4-3 gives average root mean square (RMSE) and mean bias errors (MBE) for the entire 41 days of data, where the measured values were compared with estimates from each algorithm. The measured data are 15-min integrals.

The percent mean bias error is defined by

$$
\% \text { MBE }=100\left[n^{-1} \sum_{i=1}^{n}\left(y_{i}-x_{i}\right)\right] / \bar{x},
$$

where $n$ is the sample size, $y_{i}$ is the model generated value for time interval $i, x_{i}$ is the corresponding measured value, and $\bar{x}$ is the mean measured value for a given time frame.

The percent root mean square error is given by

$$
\% \text { RMSE }=100\left[n^{-1} \sum_{i=1}^{n}\left(y_{i}-x_{i}\right)^{2}\right]^{0.5} / \bar{x},
$$

where the parameters are the same as those defined for Eq. 4-1.

One should note that the horizontal diffuse irradiances used as input to the models were calculated from global horizontal and direct normal beam values using

$$
I_{D}(0)=I_{T}(0)-I \cos Z \text {, }
$$

where all the terms are defined in Section 2.0. These calculated diffuse values are generally thought tc be more accurate than diffuse measurements using a pyranometer with a shadow band (Ryznar and Portman 1983; LeBaron, Peterson, and Dirmhirn 1980).

The evaluations using measurements from data set No. 1 were based on the observed ground albedo values. The isotropic ground term computation method was added to the Klucher and Perez algorithms to complete the comparisons. 
Table 4-2. Summary of the Models' Performance

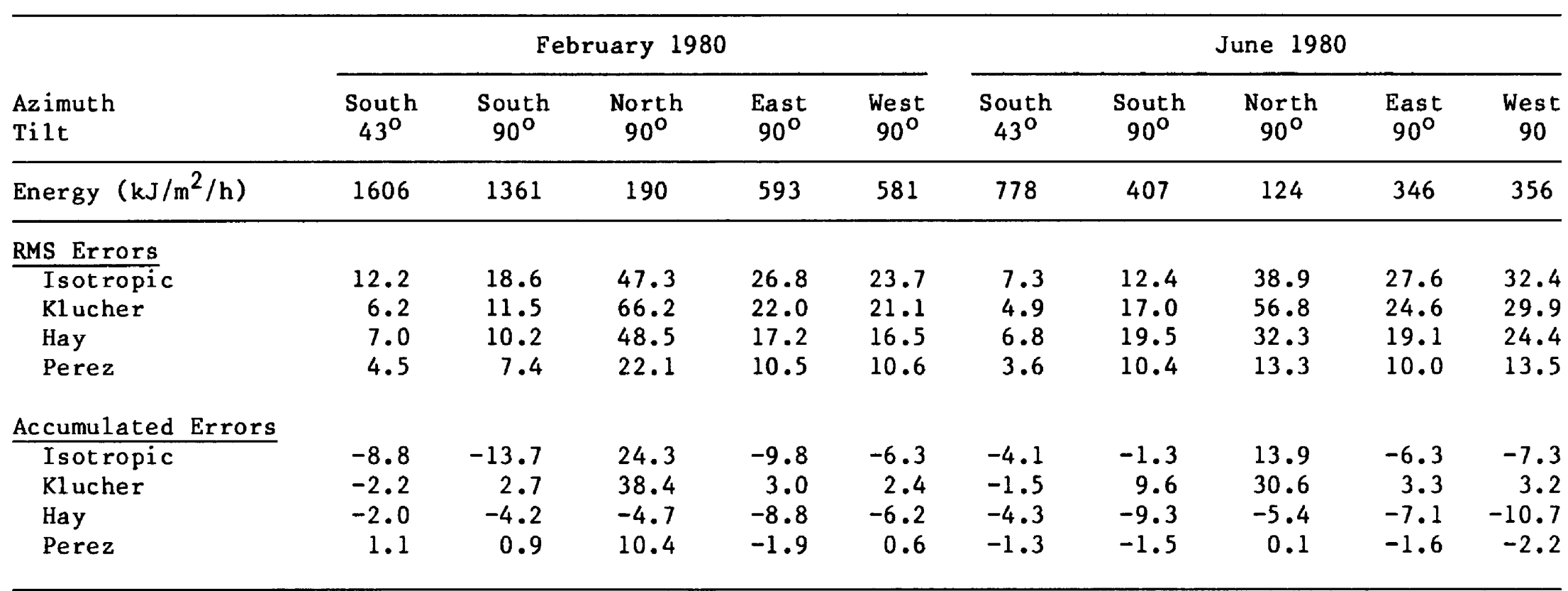

*Data from State University of New York at Albany 
Table 4-3. Conversion Algorithm Performance during 41 Days (from 22 July to 4 September 1984)

\begin{tabular}{|c|c|c|c|c|}
\hline \multirow[b]{2}{*}{ Azimuth } & \multicolumn{4}{|c|}{ Vertical Surfaces } \\
\hline & North & East & West & South \\
\hline \multicolumn{5}{|l|}{ Hourly RMS Errors (\%) } \\
\hline $\begin{array}{l}\text { Isotropic } \\
\text { Temps \& Coulson } \\
\text { K1ucher } \\
\text { Hay } \\
\text { Perez }\end{array}$ & $\begin{array}{l}61.6 \\
96.5 \\
68.9 \\
60.4 \\
55.5\end{array}$ & $\begin{array}{l}29.1 \\
31.4 \\
29.6 \\
28.3 \\
26.6\end{array}$ & $\begin{array}{l}33.0 \\
50.9 \\
34.5 \\
32.4 \\
32.2\end{array}$ & $\begin{array}{l}17.9 \\
31.9 \\
20.5 \\
18.0 \\
19.6\end{array}$ \\
\hline \multicolumn{5}{|l|}{ Mean Bias Error $(\%)$} \\
\hline $\begin{array}{l}\text { Isotropic } \\
\text { Temps \& Coulson } \\
\text { Klucher } \\
\text { Hay } \\
\text { Perez }\end{array}$ & $\begin{array}{l}18.5 \\
46.5 \\
29.2 \\
14.6 \\
18.0\end{array}$ & $\begin{array}{r}-3.0 \\
9.5 \\
2.1 \\
-3.0 \\
1.9\end{array}$ & $\begin{array}{r}3.4 \\
23.1 \\
11.1 \\
2.9 \\
10.6\end{array}$ & $\begin{array}{r}1.5 \\
15.3 \\
6.8 \\
0.9 \\
6.7\end{array}$ \\
\hline
\end{tabular}

The RMS errors given in Table 4-3 are lowest for a south-facing surface, much higher on E-W surfaces, and very high on north surfaces. This can be attributed in part to the effect of generally lower levels of irradiance available on north-facing slopes on this relative error calculation (see Table 4-4). The mean bias errors show reasonable performance on $E-S-W$ surfaces with the exception of Temps and Coulson, which has no cloud cover term.

The Perez algorithm was used with $F_{1}$ and $F_{2}$ values derived from data at SUNYA. Considering that fact, it may be that the $F$ terms are spatially and temporally conservative based on the results for the SRRL.

Table 4-4. Average Daily Total Irradiance on Vertical Surfaces Measured at the SRRL during the Period 23 July4 September 1984

\begin{tabular}{ccc}
\hline Orientation & $\begin{array}{c}\text { Irradiance } \\
\left(\mathrm{kJ} / \mathrm{m}^{2} / \text { day }\right)\end{array}$ & $\begin{array}{c}\text { Percent } \\
\text { of North }\end{array}$ \\
\hline North & 4967 & 100 \\
East & 13950 & 320 \\
South & 10495 & 241 \\
West & 8832 & 312 \\
\hline
\end{tabular}


Data from two days were taken from data set No. 2 for a more detailed evaluation of all of the algorithms, except the isotropic, since these data included north sky and north ground separation. Day 250, September 6, 1984, was generally clear although scattered clouds did develop in the afternoon. This is apparent from Figure 4-1(a), which shows the direct normal beam, global horizontal, and diffuse horizontal (calculated from Eq. 4-3) components on that day.

The comparison in Figure 4-1(b) between measured and estimated values of irradiance on a north-vertical surface is very revealing. During the morning, under clear skies, the measured values are about twice the estimated values. Since data set No. 2 did not contain observations of ground-reflected irradiance, the albedo input to the algorithms was adjusted each hour according to Figure 3-9. In general, the model results are well behaved, with Klucher and Temps and Coulson being inseparable and giving the best performance. In the afternoon, the scattered clouds produced very erratic results until late afternoon when the skies apparently cleared again. Scattered clouds are obviously not handled well by any of the algorithms.

Figures 4-2a and $b$ are similar plots for a generally cloudy day, 7 September 1984, which was previously described with reference to Figure 3-6. On this day, all of the models overestimated the irradiance on a north-vertical surface, except during relatively clear periods during the early morning and late afternoon hours. The Perez model performed the best, and the Temps and Coulson model gave the worst results.

Figures 4-3 and 4-4 provide comparisons between measured and estimated groundreflected irradiance on a north-vertical surface. Relatively good agreement is indicated between the isotropic and anisotropic methods under clear and cloudy sky conditions for north-facing surfaces. 


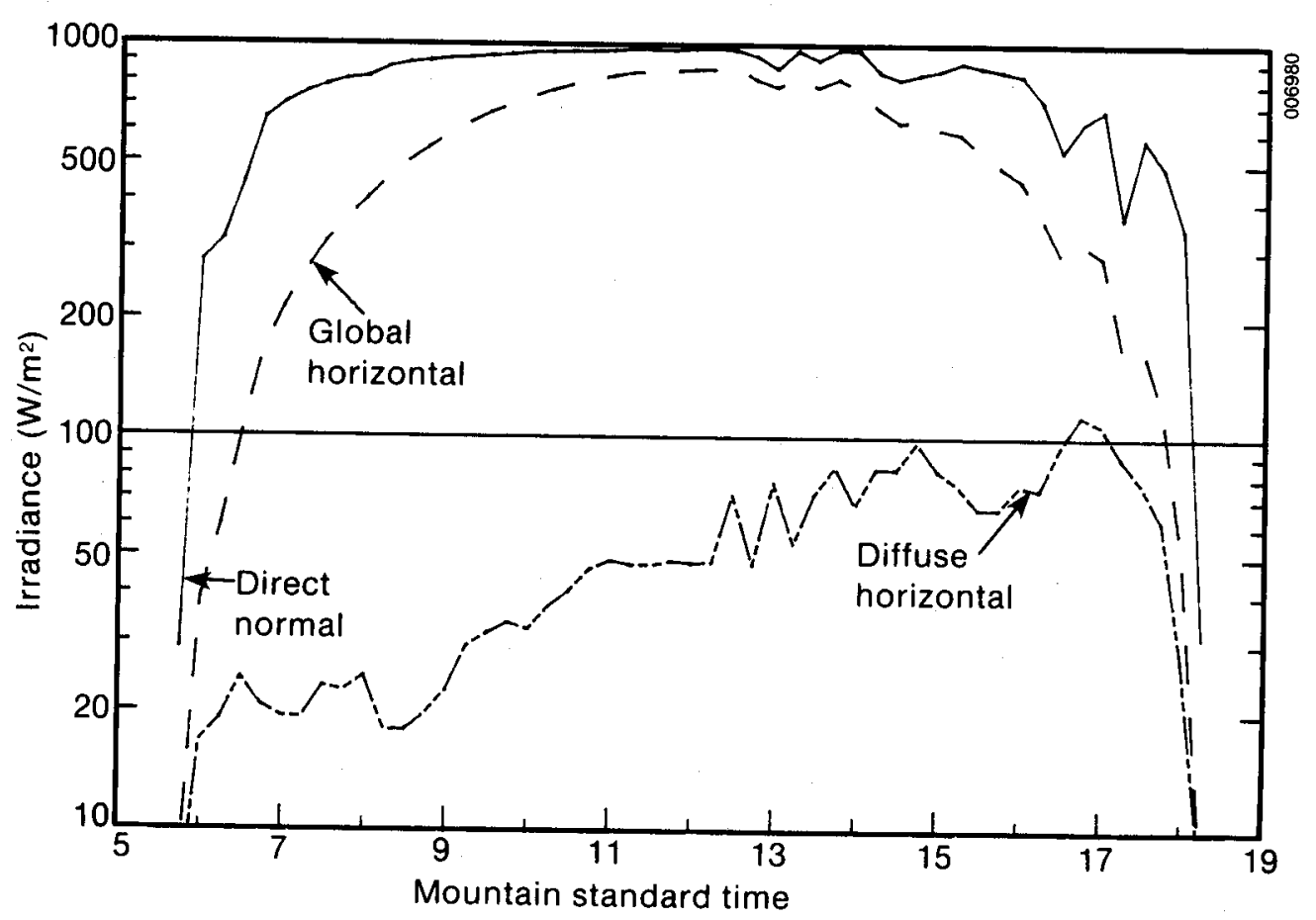

Figure 4-la. Solar Component Measurements for 6 September 1984 (Day 250)

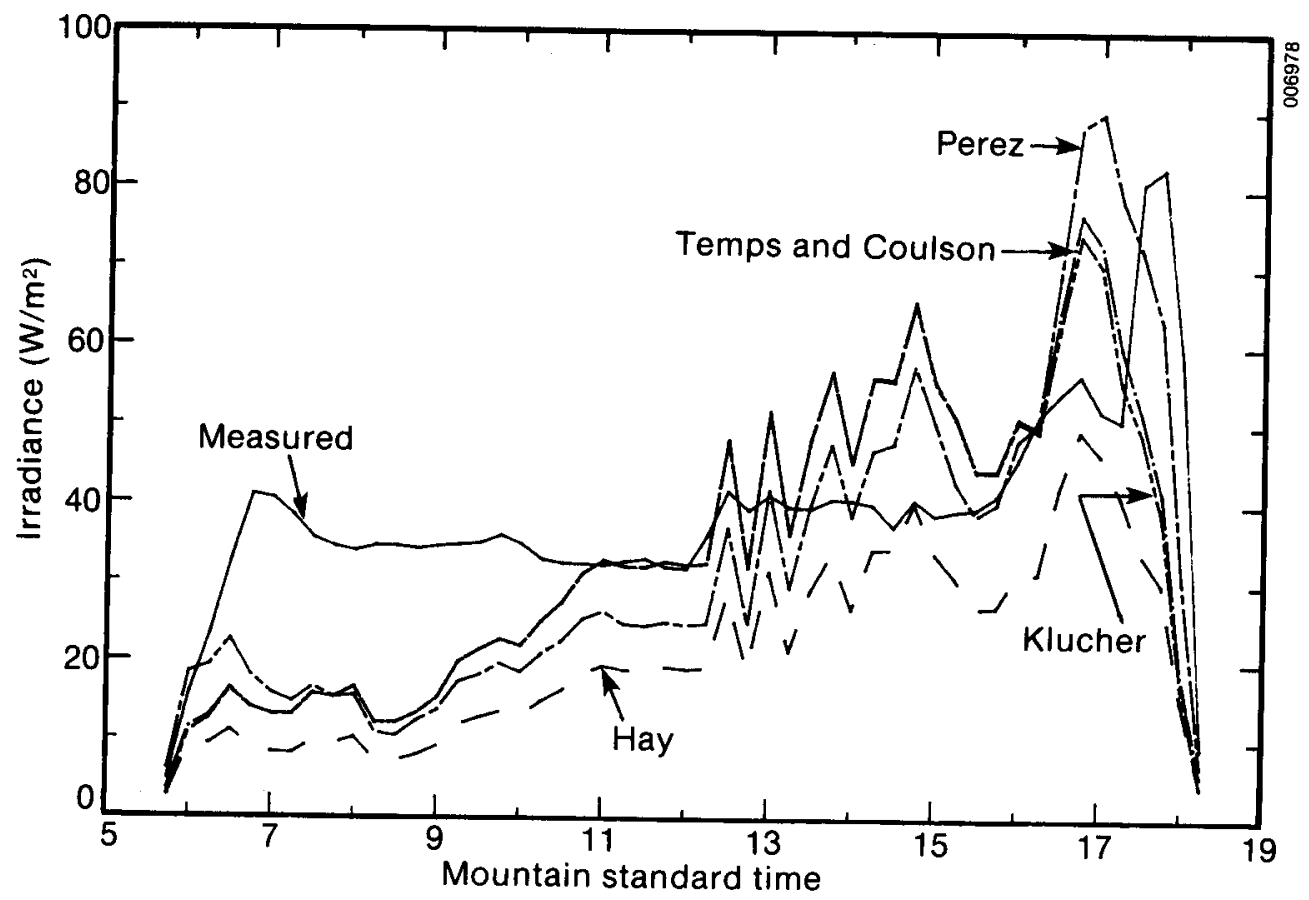

Figure 4-1b. Comparison of Measured Data for North-Facing Vertical Surface on 6 September 1984 and Tilt Model Estimates 


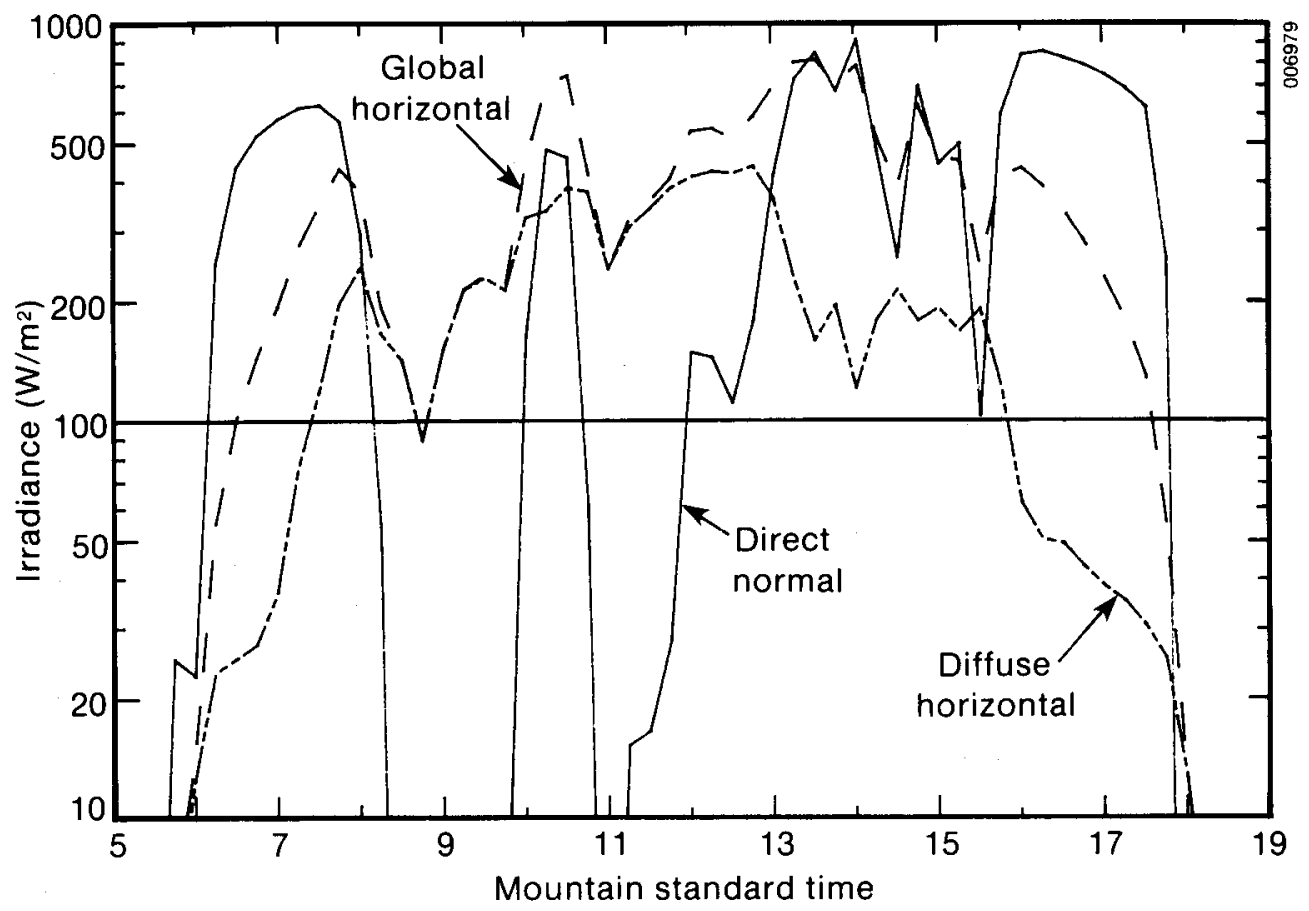

Figure 4-2a. Solar Component Measurements for 7 September 1984 (Day 251)

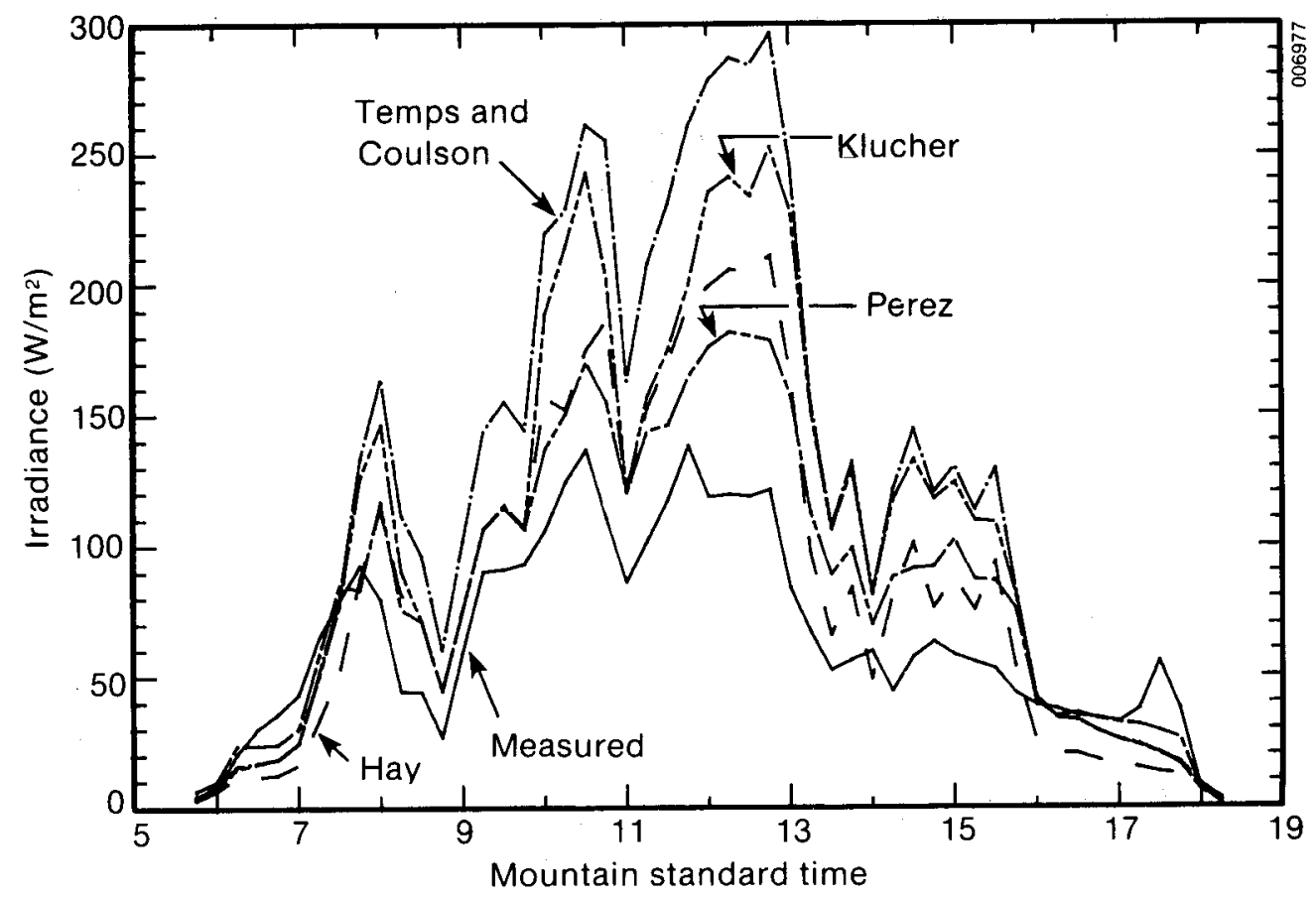

Figure 4-2b. Comparison of Measured Data for North-Facing Vertical Surface on 7 September 1984 and Tilt Model Estimates 


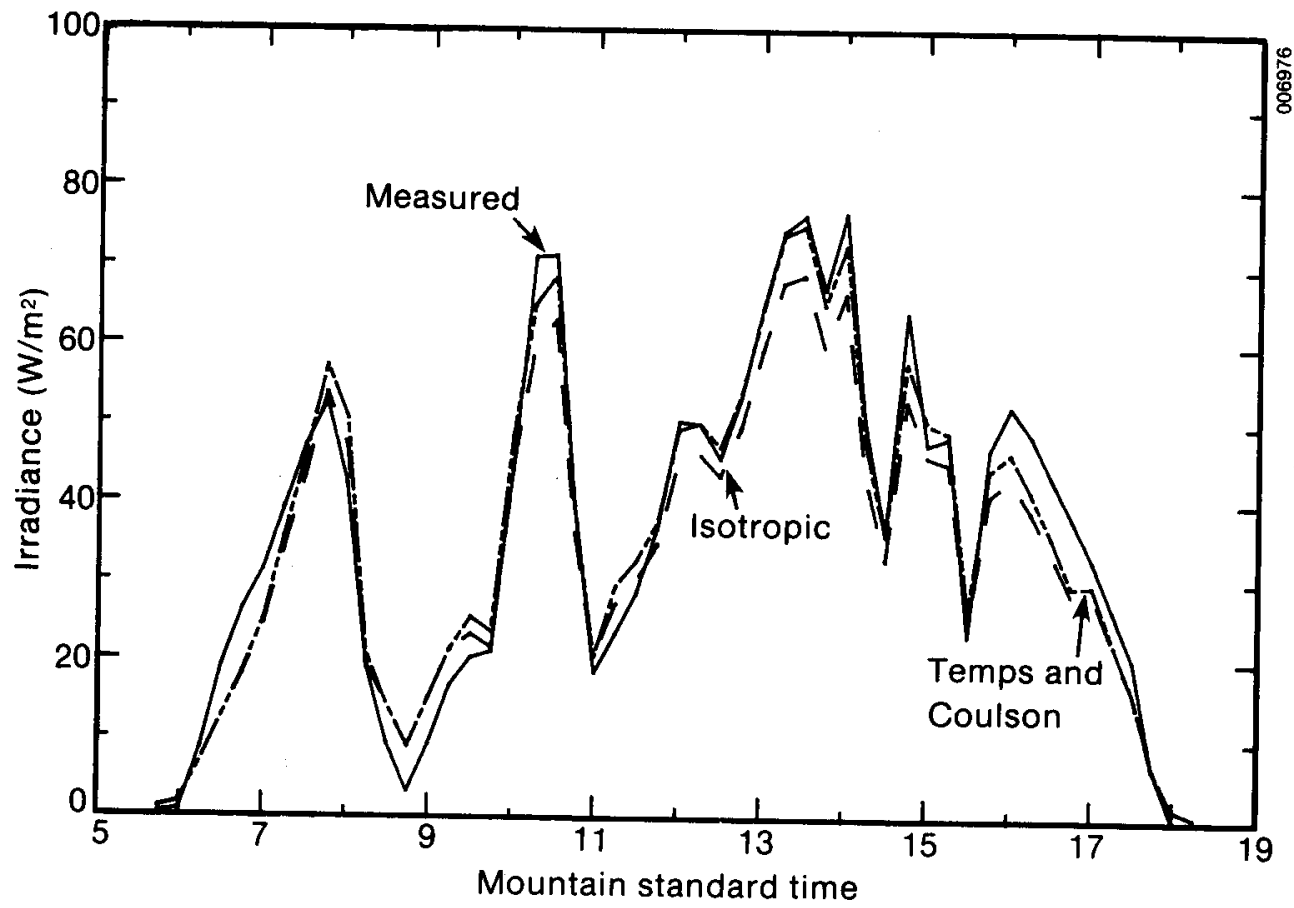

Figure 4-3. Comparison of Measured Data for North-Facing Vertical Surface on 6 September 1984 (clear sky) with Isotropic and Anisotropic Model Estimates

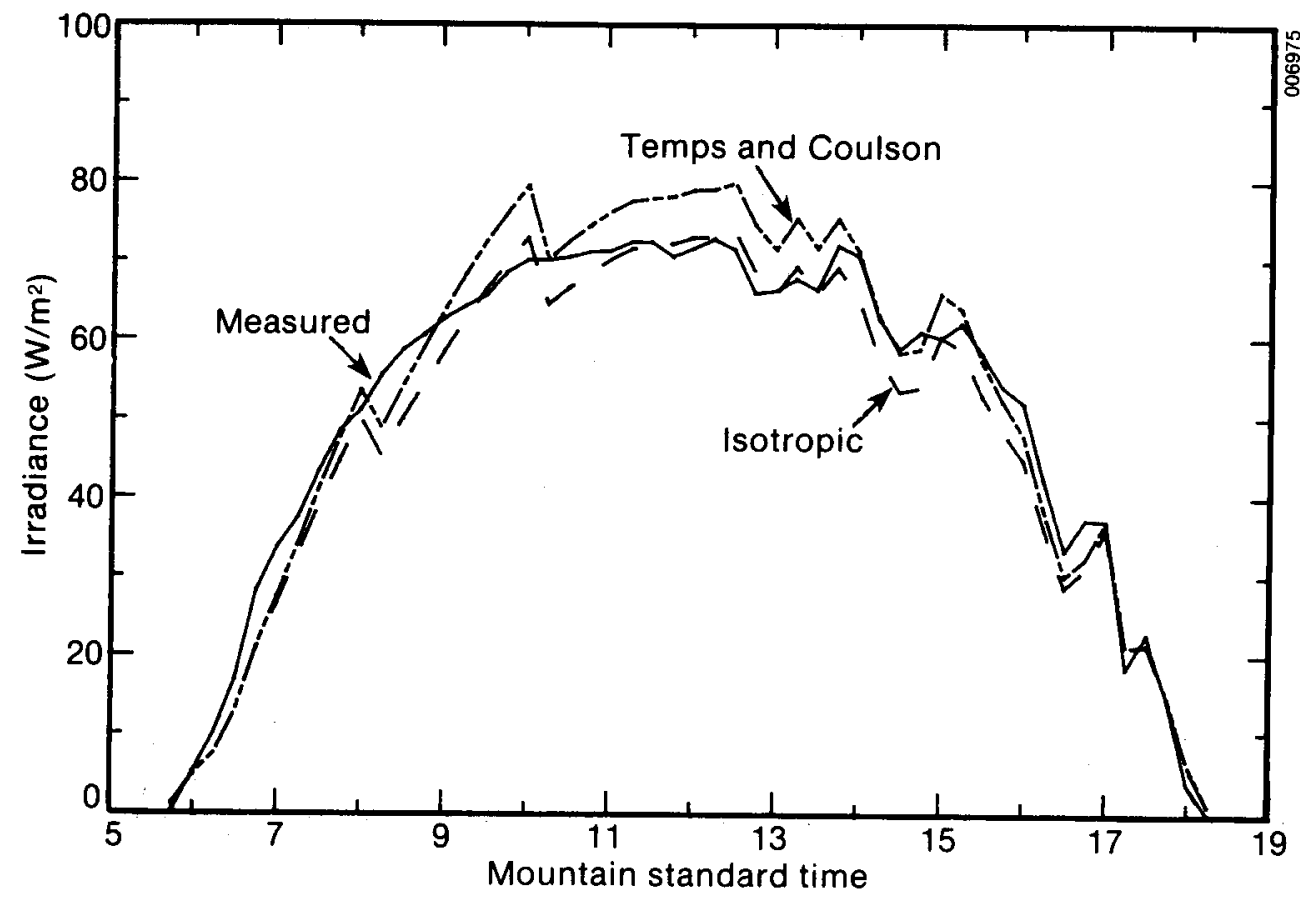

Figure 4-4. Comparison of Measured Data for North-Facing Vertical Surface on 7 September 1984 (partly cloudy sky) with Isotropic and Anisotropic Model Estimates 


\subsection{SUMMARY AND CONCLUSIONS}

Five algorithms for converting global horizontal and direct normal solar irradiance to global irradiance on tilted surfaces were evaluated using measurements from monitoring equipment newly installed at the Solar Radiation Research Laboratory. High resolution (15-min) measurements from eight thermopile radiometers oriented vertically in the four cardinal directions were available for a 169-day period ending 31 December 1984. Concurrent measurements of global horizontal and direct normal were also available for the analyses. The pyranometers used in the experiment were intercompared on horizontal, north-facing, and south-facing vertical orientations before their deployment.

The conversion algorithms each attempt to account for very complex atmospheric interactions with incoming solar radiation. The sky and ground radiance contributions to tilted surface irradiance are assumed to be isotropic (independent of direction), anisotropic (direction dependent), or a combination of the two regimes depending on the algorithm.

Results from the analysis of measurements for the period $22 \mathrm{July}$ through 4 September indicate the following algorithm performances:

- Isotropic (Liu \& Jordan)--Within measurement accuracy ( $\pm 5 \%$ ) for east, south, and west vertical surfaces. Overpredicts irradiances of north-facing surface by $18.5 \%$.

- Temps \& Coulson--Overpredicts irradiance for all orientations from $9.5 \%$ to $46.5 \%$.

- Klucher--Overpredicts irradiance for all orientations from $2.1 \%$ to $29.2 \%$.

- Hay--Within measurement accuracy for east, south, and west vertical surfaces. Overpredicts irradiance of north-facing surface by $14.6 \%$. Demonstrated least overall mean bias errors.

- Perez--Within measurement accuracy for east orientation. Overpredicts irradiance of south $(6.7 \%)$, west $(10.6 \%)$, and north $(18.0 \%)$ orientations.

The performance of all the algorithms was poorest for the north-facing vertical surfaces. The irradiance levels measured on this orientation were between two and three times less than that observed for the others on an average daily total basis. This would help explain the larger relative errors, but this orientation also places the greatest demands upon the models to account for the anisotropic distribution to diffuse sky and ground irradiances.

Because of the limited data available at this time, these results must be considered preliminary and inconclusive. Nevertheless, a fairly clear picture is emerging that indicates significant deficiencies in the diffuse sky component of all of the models. Future research should emphasize the collection of data similar to that being obtained at SRRL, which will lead to greater understanding of atmospheric processes and diffuse sky irradiance. A very desirable addition at SRRL would be the installation of an all-sky camera to photograph the sky every 15 minutes. This would improve our understanding of the data and would likely suggest modifications of the conversion algorithms. 
The collection of data during the coming months, with the change of seasons and the concomitant changes in atmospheric and ground cover conditions, should provide greater insight into the problems with the algorithms. The development of improved models should be realized in the near future if support for this kind of research continues. 


\subsection{REFERENCES}

Hay, J. E., and J. A. Davies, (1978), "Calculation of the Solar Radiation Incident on an Inclined Surface," Proc. 1st Canadian Solar Radiation Data Workshop, J. E. Hay and T. K. Won (eds.), Toronto, Canada.

Hay, J. E., and D. C. McKay, (1985), "Estimating Solar Irradiance on Inclined Surfaces, A Review and Assessment of Methodologies," International Journal of Solar Energy, Vol. 3, PP. 203-240.

Klucher, T. M., (1978), Evaluation of Models to Predict Insolation on Tilted Surfaces, NASA TM-78842.

Liu, B. Y. H., and R. C. Jordan, (1960), "The Inter-relationship and Characteristic Distribution of Direct, Diffuse, and Total Solar Radiation," Solar Energy, Vol. 4, pp. 1-19.

Perez, R., and R. Stewart, (1984), "Real Time Comparison of Models Estimating Irradiation on Sloping Surfaces," preprint from Progress in Solar Energy, Vol. VII, American Solar Energy Society.

SERI, (1981a), Solar Radiation Resource Atlas of the United States, SERI/ SP-642-1037, Golden, CO: Solar Energy Research Institute, 183 pp.

SERI, (1981b), Solar Energy Meteorological Research and Training Site Program: First Annual Report, SERI/SP-642-947, Golden, CO: Solar Energy Research Institute, $87 \mathrm{pp}$.

SERI, (1982a), Solar Energy Meteorological Research and Training Site Program: Second Annual Report, SERI/SP-290-1478, Golden, CO: Solar Energy Research Institute, 109 pp.

SERI, (1982b), International Energy Agency Conference on Pyranometer Measurements, $16-20$ March 1981, Boulder, Colorado, SERI/TR-642-1156, Golden, CO: Solar Energy Research Institute, 431 pp.

Stewart, R., and R. Perez, (1984), "Validation of an Anisotropic Mode1 Estimating Insolation on Tilted Surfaces," Progress in Solar Energy, Vol. VII, American Solar Energy Society.

Temps, R. C., and K. L. Coulson, (1977), "Solar Radiation Incident upon Slopes of Different Orientations," Solar Energy, Vol. 19, pp. 179-189. 
INTERNAL AND EXTERNAL REVIEWERS FOR

\section{PASSIVE REPORT}

Richland Perez, State Univ. of N.Y. at Albany; John Hay, Univ. of B.C., Vancouver; Gene Clark, Trinity Univ., San Antonio, Tex.; Ross McCluney, Florida Solar Energy Center, Cape Canaveral, Fla.; Bob Jones Los Alamos Labs., Los Alamos, N.M.

Claude Robbins

Kerri Hunter

Jay Burch 


\begin{tabular}{|c|c|c|c|}
\hline $\begin{array}{c}\text { Document Control } \\
\text { Page }\end{array}$ & $\begin{array}{l}\text { 1. SEAI Report No. } \\
\text { SERI/TR-215-2525 }\end{array}$ & 2. NTIS Accession No. & 3. Recipient's Accession No. \\
\hline \multirow{3}{*}{\multicolumn{3}{|c|}{$\begin{array}{l}\text { 4. Title and Subtitle } \\
\text { Measuring and Modeling Solar Irradiance on Vertical } \\
\text { Surfaces }\end{array}$}} & 5. Publication Date \\
\hline & & & \begin{tabular}{|ll}
$47 \times$ & 1986 \\
\end{tabular} \\
\hline & & & 6. \\
\hline \multicolumn{3}{|c|}{$\begin{array}{l}\text { 7. Author(s) } \\
\text { E. L. Maxwell, T. L. Stoffel, R. E. Bird }\end{array}$} & 8. Performing Organization Rept. No. \\
\hline \multirow{2}{*}{\multicolumn{3}{|c|}{$\begin{array}{l}\text { 9. Performing Organization Name and Address } \\
\text { Solar Energy Research Institute } \\
1617 \text { Cole Boulevard } \\
\text { Golden, Colorado } 80401\end{array}$}} & $\begin{array}{l}\text { 10. Project/Task/Work Unit No. } \\
3738.10\end{array}$ \\
\hline & & & $\begin{array}{l}\text { 11. Contract (C) or Grant (G) No. } \\
\text { (C) }\end{array}$ \\
\hline \multirow{2}{*}{\multicolumn{3}{|c|}{ 12. Sponsoring Organization Name and Address }} & $\begin{array}{l}\text { 13. Type of Report \& Period Covered } \\
\text { Technical Report }\end{array}$ \\
\hline & & & 14. \\
\hline \multicolumn{4}{|l|}{ 15. Supplementary Notes } \\
\hline \multicolumn{4}{|c|}{$\begin{array}{l}\text { 16. Abstract (Limit: } 200 \text { words) This report presents the first evaluations of } 5 \text { algorithms for } \\
\text { converting global horizontal and direct normal solar irradiance components to global } \\
\text { irradiance on tilted surfaces using measurements from the Solar Radiation Research } \\
\text { Laboratory (SRRL) at SERI. High resolution (15-min) measurements from } 8 \text { thermopile } \\
\text { radiometers oriented vertically in the } 4 \text { cardinal directions were available for a } \\
169-\text { day period ending } 31 \text { December } 1984 \text {. Concurrent measurements of global horizon- } \\
\text { tal and direct normal solar irradiance components were also used. The pyranometers } \\
\text { used were intercompared on horizontal, north-facing, and south-facing vertical ori- } \\
\text { entations. The conversion algorithms each attempt to account for the very complex } \\
\text { atmospheric interactions with incoming solar radiation. The sky and ground radiance } \\
\text { contributions to tilted surface are assumed to be isotropic, anisotropic, or a com- } \\
\text { bination of the two depending on the algorithm. Results from the analysis of meas- } \\
\text { urements on vertical surfaces for } 22 \text { July through } 4 \text { September indicate a general } \\
\text { overestimate (18\%-46.5\%) of solar irradiance on north-facing surfaces by all } 5 \text { of } \\
\text { the algorithms. The best agreement with measured data was demonstrated for south- } \\
\text { facing surfaces where all but one algorithm were within the present measurement by } \\
\text { as much as } 23 \% \text { of the observed } 15-m i n \text { data. }\end{array}$} \\
\hline \multirow{2}{*}{\multicolumn{4}{|c|}{$\begin{array}{l}\text { 17. Document Analysis } \\
\text { a. Descriptors Algorithms; Data; Diffuse Solar Rad } \\
\text { Pyranometers; Solar Radiation } \\
\text { b. Identifiers/Open-Ended Terms Vertical Surfaces }\end{array}$}} \\
\hline & & & \\
\hline \multicolumn{4}{|l|}{ c. UC Categories } \\
\hline \multirow{4}{*}{\multicolumn{3}{|c|}{$\begin{array}{l}\text { 18. Availability Statement } \\
\text { National Technical Information Service } \\
\text { U. S. Department of Commerce } \\
5285 \text { Port Royal Road } \\
\text { Springfield, Virginia } 22161\end{array}$}} & 19. No. of Pages \\
\hline & & & 38 \\
\hline & & & 20. Price \\
\hline & & & $\mathrm{A} 03$ \\
\hline
\end{tabular}

